Supplement of Atmos. Chem. Phys., 18, 10497-10520, 2018

https://doi.org/10.5194/acp-18-10497-2018-supplement

(C) Author(s) 2018. This work is distributed under

the Creative Commons Attribution 4.0 License.

(c) (i)
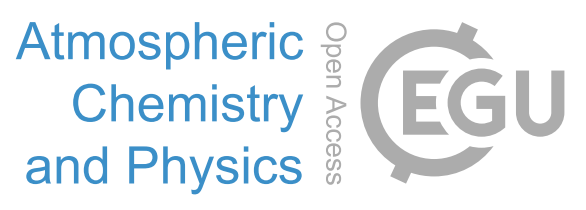

Supplement of

\title{
HTAP2 multi-model estimates of premature human mortality due to in- tercontinental transport of air pollution and emission sectors
}

Ciao-Kai Liang et al.

Correspondence to: J. Jason West (jjwest@email.unc.edu)

The copyright of individual parts of the supplement might differ from the CC BY 4.0 License. 
Table S1 -Models that reported $\mathrm{O}_{3}$ and $\mathrm{PM}_{2.5}$ (mmrpm2p5) concentrations for TF-HTAP2, with type of $\mathrm{O}_{3}$ (h- hourly, d- daily and m - monthly) and monthly $\mathrm{PM}_{2.5}$ output with the function used by models to calculate $\mathrm{PM}_{2.5}$ from species concentrations. (Data are available upon request from http://aerocom.met.no).

\begin{tabular}{|c|c|c|c|c|c|c|c|}
\hline Model & $\begin{array}{l}\text { Emission } \\
\text { perturbation } \\
\text { experiment }\end{array}$ & Institution & Contact & $\begin{array}{l}\text { Model } \\
\text { resolution } \\
\text { (lonxlat) }\end{array}$ & $\mathrm{O}_{3}$ & $\mathrm{PM}_{2.5}$ & Reference \\
\hline CAM-Chem & $-20 \%$ regions & NCAR & Louisa Emmons & $2.5^{0} \times 1.9^{0}$ & $\mathrm{~m}$ & & Tilmes et al. (2016) \\
\hline CHASER_T42 & $\begin{array}{l}-20 \% \text { regions } \\
-20 \% \text { sectors }\end{array}$ & $\begin{array}{l}\text { NAGOYA,JA } \\
\text { MSTEC,NIES }\end{array}$ & $\begin{array}{l}\text { Kengo Sudo } \\
\text { Takashi Sekiya }\end{array}$ & $2.8^{0} \times 2.8^{0}$ & $\mathrm{~h}$ & $\begin{array}{c}\mathrm{SO}_{4}+\mathrm{OC}+\mathrm{NO}_{3}+\mathrm{NH}_{4}+\mathrm{BC}+ \\
\text { Dust(fine) }+\mathrm{SS} \text { (fine) }\end{array}$ & Sudo et al. (2002) \\
\hline CHASER_T106 & $-20 \%$ regions & as above & as above & $1.1^{0} \mathrm{x} 1.1^{0}$ & $\mathrm{~m}$ & $\begin{array}{c}\mathrm{SO}_{4}+\mathrm{OC}+\mathrm{NO}_{3}+\mathrm{NH}_{4}+\mathrm{BC}+ \\
\text { Dust(fine) }+\mathrm{SS} \text { (fine) } \\
\end{array}$ & as above \\
\hline${ }^{\#} \mathrm{C}-\mathrm{IFS}$ & $-20 \%$ regions & ECMWF & Johannes Flemming & $0.7^{0} \times 0.7^{0}$ & $\mathrm{~m}$ & $\begin{array}{c}\mathrm{SS} 1+0.5^{*} \mathrm{SS} 2+\text { Dust } 1+\text { Dust } 2+ \\
0.7^{*}(\mathrm{OM} 1+\mathrm{OM} 2+\mathrm{SO} 4)\end{array}$ & Flemming et al. (2015) \\
\hline EMEPrv48 & $-20 \%$ regions & Met No & Jan Eiof Jonson & $0.5^{0} \times 0.5^{0}$ & $\mathrm{~m}$ & $\mathrm{SO}_{4}+\mathrm{OA}+\mathrm{NO}_{3}+\mathrm{NH}_{4}+\mathrm{Dust}+\mathrm{BC}+\mathrm{SS}$ & Simpson et al. (2012) \\
\hline GEOS5 & $-20 \%$ regions & NASA GSFC & $\begin{array}{l}\text { Huisheng Bian, } \\
\text { Mian Chin } \\
\text { Xiaohua Pan }\end{array}$ & $1.3^{0} \times 1.0^{0}$ & - & $1.375 * \mathrm{SO}_{4}+\mathrm{OA}+0.15 *$ Dust $+\mathrm{BC}+\mathrm{SS}$ & $\begin{array}{l}\text { Rienecker et al. (2008) } \\
\text { Colarco et al. (2010) }\end{array}$ \\
\hline $\begin{array}{l}\text { \$GEOSCHEMA } \\
\text { DJOINT }\end{array}$ & $\begin{array}{l}-20 \% \text { regions } \\
-20 \% \text { sectors }\end{array}$ & $\begin{array}{l}\text { Univ.Col. } \\
\text { Boulder }\end{array}$ & Daven Henze & $2.5^{0} \times 2.0^{0}$ & $\mathrm{~m}$ & $\begin{array}{l}1.33 *\left(\mathrm{SO}_{4}+\mathrm{NO}_{3}+\mathrm{NH}_{4}\right)+\mathrm{BCpi}+\mathrm{BCpo} \\
+1.4 *\left(1.16^{*} \mathrm{OCpi}+\mathrm{OCpo}\right)+1.16^{*} \mathrm{SO} \\
\text { A+Dust } 1+0.38 * \text { Dust } 2+1.86 \mathrm{SS}\end{array}$ & Henze et al. (2007) \\
\hline GEOS-Chem & $-20 \%$ regions & SNU & Rokjin Park & $2.5^{0} \times 2.0^{0}$ & $\mathrm{~d}$ & - & Bey et al. (2001a) \\
\hline GFDL_AM3 & $-20 \%$ regions & NOAA & Meiyun Lin & $1.2^{0} \times 1.0^{0}$ & $\mathrm{~h}$ & - & $\begin{array}{l}\text { Lin et al. (2012) } \\
\text { Lin et al. (2017) }\end{array}$ \\
\hline GOCART & $\begin{array}{l}-20 \% \text { regions } \\
-20 \% \text { sectors }\end{array}$ & NASA GSFC & Tom Kucsera & $1.3^{0} \mathrm{x} 1.0^{0}$ & - & $1.375 * \mathrm{SO}_{4}+\mathrm{OA}+0.15 *$ Dust $+\mathrm{BC}$ & Chin et al. (2002) \\
\hline HadGEM2-ES & $\begin{array}{l}-20 \% \text { regions } \\
-20 \% \text { sectors }\end{array}$ & UK Met Office & Gerd Folberth & $2.5^{0} \times 3.75^{0}$ & $\mathrm{~h}$ & - & $\begin{array}{l}\text { Collins et al. (2011) } \\
\text { Jones et al. (2011) }\end{array}$ \\
\hline OsloCTM3.v2 & $\begin{array}{l}-20 \% \text { regions } \\
-20 \% \text { sectors }\end{array}$ & CICERO & $\begin{array}{l}\text { Marianne Tronstad } \\
\text { Lund }\end{array}$ & $2.8^{0} \times 2.8^{0}$ & $\mathrm{~m}$ & - & Søvde et al. (2012) \\
\hline RAQMS & $-20 \%$ regions & $\begin{array}{l}\text { NOAA/NESD } \\
\text { IS }\end{array}$ & $\begin{array}{l}\text { Bradket Pierce } \\
\text { Allen Lenzen }\end{array}$ & $1.0^{0} \times 1.0^{0}$ & $\mathrm{~m}$ & - & Pierce et al. (2007) \\
\hline SPRINTARS & $\begin{array}{l}-20 \% \text { regions } \\
-20 \% \text { sectors }\end{array}$ & RIAM & $\begin{array}{l}\text { Toshihiko } \\
\text { Takemura }\end{array}$ & $1.1^{0} \mathrm{x} 1.1^{0}$ & - & $\mathrm{SO}_{4}+\mathrm{OA}+\mathrm{Dust}+\mathrm{BC}+\mathrm{SS}$ & $\begin{array}{l}\text { Watanabe et al. (2010) } \\
\text { Takemura et al. (2005) }\end{array}$ \\
\hline
\end{tabular}

\#The C-IFS SS1 and SS2, dust 1 and dust 2 refer to two modes of aerosol size distribution.

${ }^{\$}$ The GEOSCHEMADJOINT pi and po of BC and OC refer to hydrophilic and hydrophobic components, and dust 1 and dust 2 refer to two modes of aerosol size distribution. 
Table S2. Statistical model evaluation for the maximum 3-month average of daily 1-hour maximum ozone, comparing TOAR observations with individual model simulations and the ensemble average, in TF-HTAP2 regions (Figure. S2).

Ensemble CAMchem CHASER_T42 CHASER_T106 C-IFS_v2 EMEP_rv48 GEOSCHEMA GEOS-Chem GFDL_AM3 HadGEM2-ES OsloCTM3.v2 RAQMS

\begin{tabular}{|c|c|c|c|c|c|c|c|c|c|c|c|c|c|}
\hline & $\operatorname{NMB}(\%)$ & $14.1 \%$ & $21.9 \%$ & $21.1 \%$ & $30.8 \%$ & $-8.9 \%$ & $20.1 \%$ & $31.6 \%$ & $32.3 \%$ & $25.1 \%$ & $5.4 \%$ & $-18.1 \%$ & $-6.3 \%$ \\
\hline \multirow{2}{*}{ (1,417 sites) } & $\operatorname{NME}(\%)$ & $17.6 \%$ & $22.7 \%$ & $25.9 \%$ & $32.3 \%$ & $16.6 \%$ & $24.9 \%$ & $32.5 \%$ & $33.5 \%$ & $26.4 \%$ & $13.8 \%$ & $21.0 \%$ & $12.5 \%$ \\
\hline & $\mathrm{R}$ & 0.52 & 0.63 & 0.38 & 0.44 & 0.29 & 0.42 & 0.51 & 0.47 & 0.49 & 0.6 & 0.35 & 0.46 \\
\hline \multirow{3}{*}{$\begin{array}{c}\text { EUR } \\
(1,887 \text { sites })\end{array}$} & $\operatorname{NMB}(\%)$ & $4.3 \%$ & $9.0 \%$ & $7.0 \%$ & $21.3 \%$ & $-23.0 \%$ & $15.8 \%$ & $14.9 \%$ & $10.1 \%$ & $14.0 \%$ & $11.7 \%$ & $-24.1 \%$ & $-10.1 \%$ \\
\hline & $\operatorname{NME}(\%)$ & $9.8 \%$ & $12.5 \%$ & $13.2 \%$ & $22.7 \%$ & $24.5 \%$ & $17.8 \%$ & $16.5 \%$ & $13.3 \%$ & $15.4 \%$ & $17.7 \%$ & $27.1 \%$ & $15.1 \%$ \\
\hline & $\mathrm{R}$ & 0.55 & 0.55 & 0.41 & 0.48 & 0.28 & 0.47 & 0.48 & 0.49 & 0.61 & 0.31 & 0.37 & 0.48 \\
\hline \multirow{3}{*}{$\begin{array}{c}\text { SAS } \\
\text { (4 sites) }\end{array}$} & $\operatorname{NMB}(\%)$ & $25.3 \%$ & $37.9 \%$ & $16.1 \%$ & $29.1 \%$ & $-2.4 \%$ & $40.0 \%$ & $42.0 \%$ & $40.6 \%$ & $45.0 \%$ & $31.1 \%$ & $-24.5 \%$ & $23.9 \%$ \\
\hline & $\operatorname{NME}(\%)$ & $25.3 \%$ & $37.9 \%$ & $16.1 \%$ & $29.1 \%$ & $15.6 \%$ & $40.0 \%$ & $42.0 \%$ & $40.6 \%$ & $45.0 \%$ & $41.6 \%$ & $24.5 \%$ & $23.9 \%$ \\
\hline & $\mathrm{R}$ & 0.30 & 0.41 & 0.67 & 0.31 & 0.14 & 0.28 & 0.52 & 0.40 & 0.03 & -0.29 & -0.22 & 0.45 \\
\hline \multirow{3}{*}{$\begin{array}{c}\text { EAS } \\
(1,156 \text { sites })\end{array}$} & $\operatorname{NMB}(\%)$ & $5.2 \%$ & $10.8 \%$ & $1.2 \%$ & $19.8 \%$ & $-26.4 \%$ & $-3.1 \%$ & $24.5 \%$ & $13.0 \%$ & $18.7 \%$ & $10.9 \%$ & $4.0 \%$ & $-16.5 \%$ \\
\hline & $\operatorname{NME}(\%)$ & $13.2 \%$ & $16.1 \%$ & $16.5 \%$ & $22.6 \%$ & $28.3 \%$ & $17.0 \%$ & $26.1 \%$ & $18.4 \%$ & $19.9 \%$ & $16.9 \%$ & $14.8 \%$ & $22.3 \%$ \\
\hline & $\mathrm{R}$ & 0.08 & 0.12 & 0.05 & 0.14 & -0.15 & -0.06 & 0.07 & 0.06 & 0.25 & 0.03 & 0.12 & -0.09 \\
\hline \multirow{3}{*}{$\begin{array}{c}\text { MDE } \\
\text { (13 sites) }\end{array}$} & $\operatorname{NMB}(\%)$ & $4.9 \%$ & $20.8 \%$ & $4.3 \%$ & $7.9 \%$ & $-30.5 \%$ & $6.7 \%$ & $21.2 \%$ & $16.0 \%$ & $0.1 \%$ & $20.3 \%$ & $10.4 \%$ & $-22.9 \%$ \\
\hline & $\operatorname{NME}(\%)$ & $12.2 \%$ & $22.1 \%$ & $14.1 \%$ & $13.7 \%$ & $30.5 \%$ & $18.7 \%$ & $22.0 \%$ & $17.6 \%$ & $15.0 \%$ & $20.7 \%$ & $16.9 \%$ & $27.2 \%$ \\
\hline & $\mathrm{R}$ & -0.09 & -0.05 & -0.49 & -0.2 & -0.09 & -0.21 & 0.26 & 0.17 & -0.1 & 0.54 & 0.18 & -0.21 \\
\hline \multirow{3}{*}{$\begin{array}{c}\text { RBU } \\
\text { (4 sites) }\end{array}$} & $\operatorname{NMB}(\%)$ & $-11.2 \%$ & $-12.2 \%$ & $-9.7 \%$ & $-6.9 \%$ & $-27.7 \%$ & $5.4 \%$ & $2.4 \%$ & $0.1 \%$ & $1.4 \%$ & $-23.1 \%$ & $-35.3 \%$ & $-17.9 \%$ \\
\hline & $\operatorname{NME}(\%)$ & $11.2 \%$ & $12.2 \%$ & $14.3 \%$ & $7.3 \%$ & $27.7 \%$ & $6.4 \%$ & $2.4 \%$ & $1.0 \%$ & $9.1 \%$ & $23.1 \%$ & $35.3 \%$ & $17.9 \%$ \\
\hline & $\mathrm{R}$ & 0.98 & 1.00 & 0.71 & 0.97 & 0.26 & 0.94 & 1.00 & 1.00 & 0.92 & 0.97 & 0.67 & 0.93 \\
\hline \multirow{3}{*}{$\begin{array}{c}\text { World } \\
(4,655 \text { sites })\end{array}$} & $\operatorname{NMB}(\%)$ & $7.3 \%$ & $13.1 \%$ & $9.2 \%$ & $23.0 \%$ & $-19.4 \%$ & $11.7 \%$ & $22.5 \%$ & $17.6 \%$ & $19.0 \%$ & $9.5 \%$ & $-14.9 \%$ & $-10.8 \%$ \\
\hline & $\operatorname{NME}(\%)$ & $13.2 \%$ & $16.6 \%$ & $18.0 \%$ & $25.3 \%$ & $23.0 \%$ & $19.8 \%$ & $23.9 \%$ & $20.8 \%$ & $20.4 \%$ & $16.5 \%$ & $21.9 \%$ & $16.4 \%$ \\
\hline & $\mathrm{R}$ & 0.53 & 0.56 & 0.36 & 0.47 & 0.24 & 0.30 & 0.51 & 0.45 & 0.55 & 0.48 & 0.47 & 0.38 \\
\hline
\end{tabular}


Table S3. Statistical model evaluation for the annual average $\mathrm{PM}_{2.5}$, comparing GBD2013 observations with individual model simulations and the ensemble average in each TF-HTAP2 region (Figure. S2).

\begin{tabular}{|c|c|c|c|c|c|c|c|c|c|c|}
\hline & & Ensemble & CHASER & CHASER_t106 & C-IFS_v2 & EMEP_rv48 & $\begin{array}{c}\text { GEOSCHEMA } \\
\text { DJOINT }\end{array}$ & GEOS5 & GOCARTv5 & SPRINTARS \\
\hline \multirow{3}{*}{$\begin{array}{c}\text { NAM } \\
\text { (757 sites) }\end{array}$} & $\operatorname{NMB}(\%)$ & $-10.5 \%$ & $7.4 \%$ & $13.9 \%$ & $-28.1 \%$ & $-10.1 \%$ & $11.6 \%$ & $-7.5 \%$ & $-24.9 \%$ & $-46.6 \%$ \\
\hline & $\operatorname{NME}(\%)$ & $27.6 \%$ & $39.2 \%$ & $39.5 \%$ & $45.8 \%$ & $29.0 \%$ & $48.5 \%$ & $30.2 \%$ & $35.5 \%$ & $47.8 \%$ \\
\hline & $\mathrm{R}$ & 0.50 & 0.42 & 0.43 & 0.13 & 0.56 & 0.45 & 0.36 & 0.44 & 0.47 \\
\hline \multirow{3}{*}{$\begin{array}{c}\text { EUR } \\
(1,580 \text { sites })\end{array}$} & $\operatorname{NMB}(\%)$ & $-36.0 \%$ & $-27.6 \%$ & $-29.6 \%$ & $-52.3 \%$ & $-45.6 \%$ & $31.9 \%$ & $-34.0 \%$ & $-55.1 \%$ & $-76.0 \%$ \\
\hline & $\operatorname{NME}(\%)$ & $39.7 \%$ & $35.5 \%$ & $37.2 \%$ & $58.6 \%$ & $47.3 \%$ & $56.4 \%$ & $41.1 \%$ & $56.8 \%$ & $76.0 \%$ \\
\hline & $\mathrm{R}$ & 0.73 & 0.49 & 0.46 & 0.47 & 0.55 & 0.25 & 0.65 & 0.67 & 0.64 \\
\hline \multirow{3}{*}{$\begin{array}{c}\text { SAS } \\
\text { (189 sites })\end{array}$} & $\operatorname{NMB}(\%)$ & $19.4 \%$ & $32.3 \%$ & $49.7 \%$ & $8.6 \%$ & $26.1 \%$ & $39.5 \%$ & $36.6 \%$ & $-2.5 \%$ & $-35.0 \%$ \\
\hline & $\operatorname{NME}(\%)$ & $40.4 \%$ & $48.8 \%$ & $61.4 \%$ & $39.5 \%$ & $48.1 \%$ & $55.5 \%$ & $54.6 \%$ & $33.6 \%$ & $50.2 \%$ \\
\hline & $\mathrm{R}$ & 0.60 & 0.55 & 0.57 & 0.49 & 0.52 & 0.60 & 0.45 & 0.56 & -0.09 \\
\hline \multirow{3}{*}{$\begin{array}{c}\text { EAS } \\
\text { (390 sites) }\end{array}$} & $\operatorname{NMB}(\%)$ & $-10.9 \%$ & $2.6 \%$ & $21.0 \%$ & $-50.4 \%$ & $-12.1 \%$ & $29.5 \%$ & $-9.1 \%$ & $-21.8 \%$ & $-46.5 \%$ \\
\hline & $\operatorname{NME}(\%)$ & $28.7 \%$ & $31.7 \%$ & $40.5 \%$ & $51.8 \%$ & $37.2 \%$ & $59.9 \%$ & $35.0 \%$ & $32.0 \%$ & $49.9 \%$ \\
\hline & $\mathrm{R}$ & 0.65 & 0.57 & 0.56 & 0.61 & 0.63 & 0.56 & 0.61 & 0.63 & 0.48 \\
\hline \multirow{3}{*}{$\begin{array}{c}\text { MDE } \\
\text { (29 sites) }\end{array}$} & $\operatorname{NMB}(\%)$ & $-11.1 \%$ & $-30.2 \%$ & $-42.6 \%$ & $22.8 \%$ & $31.5 \%$ & $-52.6 \%$ & $12.3 \%$ & $20.8 \%$ & $-50.5 \%$ \\
\hline & $\operatorname{NME}(\%)$ & $21.2 \%$ & $37.9 \%$ & $44.4 \%$ & $34.1 \%$ & $46.1 \%$ & $52.6 \%$ & $22.8 \%$ & $27.6 \%$ & $50.5 \%$ \\
\hline & $\mathrm{R}$ & 0.84 & 0.33 & 0.74 & 0.81 & 0.43 & 0.54 & 0.91 & 0.91 & 0.67 \\
\hline \multirow{3}{*}{$\begin{array}{c}\text { RBU } \\
\text { (2 sites) }\end{array}$} & $\operatorname{NMB}(\%)$ & $-49.7 \%$ & $-42.7 \%$ & $-37.4 \%$ & $-58.8 \%$ & $-64.6 \%$ & $-19.8 \%$ & $-45.4 \%$ & $-55.0 \%$ & $-74.1 \%$ \\
\hline & $\operatorname{NME}(\%)$ & $49.7 \%$ & $42.7 \%$ & $37.4 \%$ & $58.8 \%$ & $64.6 \%$ & $38.2 \%$ & $45.4 \%$ & $55.0 \%$ & $74.1 \%$ \\
\hline & $\mathrm{R}$ & 1.00 & 1.00 & 1.00 & 1.00 & 1.00 & 1.00 & 1.00 & 1.00 & 1.00 \\
\hline \multirow{3}{*}{$\begin{array}{c}\text { World } \\
(3,157 \text { sites })\end{array}$} & $\operatorname{NMB}(\%)$ & $-23.1 \%$ & $-12.7 \%$ & $-7.4 \%$ & $-39.7 \%$ & $-26.3 \%$ & $20.3 \%$ & $-18.7 \%$ & $-39.4 \%$ & $-60.9 \%$ \\
\hline & $\operatorname{NME}(\%)$ & $35.4 \%$ & $37.4 \%$ & $40.0 \%$ & $52.2 \%$ & $41.8 \%$ & $55.1 \%$ & $38.6 \%$ & $46.6 \%$ & $62.9 \%$ \\
\hline & $\mathrm{R}$ & 0.77 & 0.71 & 0.71 & 0.66 & 0.71 & 0.65 & 0.74 & 0.77 & 0.63 \\
\hline
\end{tabular}


Table S4 - Regional and global population (for age 25 and older) and average causespecific baseline mortality rates (also for age 25 and older): chronic respiratory mortality (RESP), ischemic heart disease (IHD), cerebrovascular disease (STROKE), chronic obstructive pulmonary disease (COPD) and lung cancer (LC).

\begin{tabular}{|c|c|c|c|c|c|c|}
\hline \multirow{2}{*}{ Regions } & \multirow{2}{*}{$\begin{array}{c}\text { Population } \\
\text { (million people) }\end{array}$} & \multicolumn{5}{|c|}{ Mortality (deaths per year per 1,000 people). } \\
\cline { 3 - 7 } & 231.7 & RESP & IHD & COPD & STROKE & LC \\
\hline NAM & 433.3 & 0.88 & 2.71 & 0.73 & 0.84 & 0.80 \\
\hline EUU & 730.9 & 1.73 & 1.68 & 1.33 & 0.94 & 0.14 \\
\hline SAS & $1,047.3$ & 1.18 & 1.18 & 1.05 & 2.07 & 0.63 \\
\hline EAS & 102.4 & 0.34 & 2.11 & 0.16 & 1.05 & 0.13 \\
\hline MDE & 194.4 & 0.54 & 6.80 & 0.42 & 3.64 & 0.47 \\
\hline RBU & $3,838.8$ & 0.97 & 1.86 & 0.76 & 1.57 & 0.41 \\
\hline World & -0.7 & & & &
\end{tabular}

Sources: Population - Oak Ridge National Laboratory's Landscan 2011 Global Population Dataset (Bright et al. 2012). Baseline mortality rates - Cause-specific baseline mortality rates for 187 countries (IHME, 2013) 
Table S5 - Difference in global population-weighted anthropogenic $\mathrm{O}_{3}$ concentrations (ppb) for 20\% emission reduction scenarios relative to the baseline for the year 2010. $\mathrm{O}_{3}$ is seasonal average of 1-hr. daily maximum $\mathrm{O}_{3}$ for consecutive 6 months, a metric commonly used in health impact evaluations. All numbers are rounded to the nearest hundredth.

\begin{tabular}{|c|c|c|c|c|c|c|c|c|c|c|c|}
\hline \multirow{2}{*}{ Models } & \multirow[b]{2}{*}{ BASE } & \multicolumn{10}{|c|}{$20 \%$ emission reduction scenarios } \\
\hline & & GLO & NAM & EUR & SAS & EAS & MDE & RBU & PIN & TRN & RES \\
\hline CAM-Chem & 56.49 & -2.29 & -0.10 & -0.05 & -0.58 & -0.23 & -0.02 & 0.06 & --- & --- & --- \\
\hline CHASER_T42 & 56.27 & -3.64 & -0.26 & -0.22 & -1.06 & -1.04 & -0.11 & -0.08 & -1.51 & -1.35 & -0.53 \\
\hline CHASER_T106 & 56.38 & -3.30 & -0.23 & -0.19 & -1.03 & -0.91 & --- & --- & --- & --- & --- \\
\hline C-IFS & 38.73 & -1.95 & -0.11 & -0.04 & -0.75 & -0.28 & --- & --- & --- & --- & --- \\
\hline EMEPrv48 & 59.41 & -3.13 & -0.24 & -0.18 & -0.93 & -0.77 & -0.09 & -0.13 & --- & --- & --- \\
\hline $\begin{array}{l}\text { GEOSCHEMADJ } \\
\text { OINT }\end{array}$ & 58.97 & -2.36 & -0.18 & -0.08 & -0.69 & -0.41 & -0.09 & -0.03 & -0.83 & -0.92 & -0.46 \\
\hline GEOS-Chem & 57.59 & -2.45 & -0.21 & --- & --- & -0.62 & --- & --- & --- & --- & --- \\
\hline GFDL_AM3 & 63.75 & -3.15 & -0.22 & -0.20 & --- & -0.49 & --- & --- & --- & --- & --- \\
\hline HadGEM2-ES & 58.03 & -3.18 & -0.23 & -0.20 & -1.30 & -0.51 & -0.07 & -0.09 & -1.02 & -1.29 & -0.81 \\
\hline OsloCTM3.v2 & 38.95 & -2.79 & -0.16 & -0.12 & -0.87 & -0.63 & -0.14 & -0.03 & -1.09 & -0.97 & -0.47 \\
\hline RAQMS & 46.62 & --- & --- & --- & --- & -0.45 & --- & --- & --- & --- & --- \\
\hline Multi-model mean & $53.74 \pm 8.03$ & $-2.82 \pm 0.53$ & $-0.19 \pm 0.07$ & $-0.14 \pm 0.07$ & $-0.90 \pm 0.22$ & $-0.58 \pm 0.25$ & $-0.09 \pm 0.04$ & $-0.05 \pm 0.06$ & $-1.11 \pm 0.25$ & $-1.13 \pm 0.19$ & $-0.57 \pm 0.14$ \\
\hline
\end{tabular}


Table S6 - Difference in global population-weighted anthropogenic $\mathrm{PM}_{2.5}$ concentrations $\left(\mu \mathrm{g} / \mathrm{m}^{3}\right)$ for $20 \%$ emission reduction scenarios relative to the baseline for the year 2010. $\mathrm{PM}_{2.5}$ is the annual average. All numbers are rounded to the nearest hundredth.

\begin{tabular}{|c|c|c|c|c|c|c|c|c|c|c|c|}
\hline \multirow{2}{*}{ Models } & \multirow[b]{2}{*}{ BASE } & \multicolumn{10}{|c|}{$20 \%$ emission reduction scenarios } \\
\hline & & GLO & NAM & EUR & SAS & EAS & MDE & $\mathrm{RBU}$ & PIN & TRN & RES \\
\hline CHASER_T42 & 27.02 & -4.09 & -0.12 & -0.18 & -1.31 & -1.77 & -0.12 & -0.05 & -1.94 & -0.47 & -1.28 \\
\hline CHASER_T106 & 30.49 & -4.64 & -0.11 & -0.18 & -1.48 & -2.00 & --- & --- & --- & --- & --- \\
\hline C-IFS & 23.67 & -1.42 & -0.03 & -0.03 & -0.47 & -0.56 & --- & --- & --- & --- & --- \\
\hline EMEPrv48 & 26.55 & -4.23 & -0.08 & -0.14 & -1.30 & -1.54 & -0.08 & -0.07 & --- & --- & --- \\
\hline GEOS5 & 30.85 & -3.64 & -0.05 & -0.08 & -1.39 & -1.42 & -0.05 & -0.03 & --- & --- & --- \\
\hline $\begin{array}{l}\text { GEOSCHEMADJO } \\
\text { INT }\end{array}$ & 30.36 & -6.02 & -0.15 & -0.34 & -2.05 & -2.79 & -0.12 & -0.09 & -2.07 & -0.99 & -1.54 \\
\hline GOCART & 24.42 & -2.34 & -0.04 & -0.07 & -0.81 & -0.96 & -0.05 & -0.03 & -1.06 & -0.10 & -1.18 \\
\hline SPRINTARS & 14.50 & -1.51 & -0.03 & -0.06 & -0.45 & -0.59 & -0.04 & -0.01 & -0.76 & -0.06 & -0.68 \\
\hline Multi-model mean & $25.98 \pm 5.05$ & $-3.49 \pm 1.51$ & $-0.08 \pm 0.04$ & $-0.13 \pm 0.09$ & $-1.16 \pm 0.51$ & $-1.45 \pm 0.71$ & $-0.08 \pm 0.03$ & $-0.05 \pm 0.03$ & $-1.46 \pm 0.56$ & $-0.40 \pm 0.37$ & $-1.17 \pm 0.31$ \\
\hline
\end{tabular}


Table S7 - Global O3-related respiratory mortality for the year 2010 baseline, showing the deterministic mean. All numbers are rounded to three significant figures or the nearest 100 deaths.

\begin{tabular}{|c|c|c|c|c|c|c|c|}
\hline \multirow{2}{*}{ Models } & \multicolumn{7}{|c|}{ Receptors } \\
\hline & World & NAM & EUR & SAS & EAS & MDE & $\mathrm{RBU}$ \\
\hline CAM-Chem & 396,000 & 22,600 & 16,600 & 167,000 & 168,000 & 3,700 & 3,400 \\
\hline CHASER_T42 & 355,000 & 23,200 & 24,000 & 150,000 & 125,000 & 5,700 & 5,200 \\
\hline CHASER_T106 & 394,000 & 22,500 & 20,300 & 157,000 & 172,000 & 3,600 & 4,400 \\
\hline C-IFS & 96,700 & 6,000 & 1,400 & 64,400 & 18,700 & 800 & 200 \\
\hline EMEPrv48 & 418,000 & 15,400 & 17,600 & 195,000 & 146,000 & 3,300 & 5,200 \\
\hline GEOSCHEMADJOINT & 391,000 & 22,400 & 17,700 & 178,000 & 132,000 & 5,000 & 4,900 \\
\hline GEOS-Chem & 381,000 & 22,600 & 15,200 & 178,000 & 130,000 & 4,500 & 4,400 \\
\hline GFDL_AM3 & 494,000 & 22,200 & 23,400 & 224,000 & 170,000 & 3,800 & 5,000 \\
\hline HadGEM2-ES & 390,000 & 14,200 & 19,700 & 211,000 & 108,000 & 4,700 & 2,500 \\
\hline OsloCTM3.v2 & 73,900 & 3,200 & 2,300 & 36,800 & 23,600 & 2,300 & 100 \\
\hline RAQMS & 202,000 & 5,700 & 5,500 & 118,900 & 56,300 & 1,200 & 1,400 \\
\hline Multi-model mean & $326,000 \pm 131,000$ & $16,400 \pm 7,600$ & $14,900 \pm 7,700$ & $153,000 \pm 55,700$ & $114,000 \pm 53,700$ & $3,500 \pm 1,500$ & $3,300 \pm 1,900$ \\
\hline
\end{tabular}


Table S8 - Global PM 2.5-related mortality (IHD+Stroke+COPD+LC) for the year 2010 baseline, showing the deterministic mean. All numbers are rounded to three significant figures or the nearest 100 deaths.

\begin{tabular}{lcccccc}
\multicolumn{1}{c}{ Models } & World & NAM & EUR & SAS & EAS & MDE \\
\cline { 2 - 7 } CHASER_T42 & $3,070,000$ & 98,700 & 230,000 & 797,000 & $1,320,000$ & 67,000 \\
\hline CHASER_T106 & $3,270,000$ & 109,000 & 229,000 & 845,000 & $1,400,000$ & 63,700 \\
\hline C-IFS & $2,420,000$ & 16,800 & 144,000 & 713,000 & 781,000 & 106,000 \\
\hline EMEPrv48 & $2,780,000$ & 80,600 & 150,000 & 778,000 & $1,170,000$ & 1000 \\
\hline GEOS5 & $3,190,000$ & 67,600 & 213,000 & 825,000 & $1,220,000$ & 101,000 \\
\hline GEOSCHEMADJOINT & $3,230,000$ & 114,000 & 381,000 & 797,000 & $1,430,000$ & 41,000 \\
\hline GOCART & $2,710,000$ & 39,400 & 127,000 & 718,000 & $1,120,000$ & 2800 \\
\hline SPRINTARS & $1,720,000$ & 27,400 & 25,600 & 477,000 & 812,000 & 106,000 \\
\hline \multicolumn{1}{c}{ Multi-model mean } & $2,840,000 \pm 494,000$ & $77,400 \pm 35,300$ & $180,000 \pm 900$ & 2000 \\
\hline
\end{tabular}


Table S9-Global avoided $\mathrm{O}_{3}$-related respiratory mortality in 20\% emission reduction scenarios for the year 2010, showing the deterministic mean. All numbers are rounded to three significant figures or the nearest 100 deaths.

\begin{tabular}{|c|c|c|c|c|c|c|c|c|c|c|}
\hline \multirow{2}{*}{ Models } & \multicolumn{10}{|c|}{$20 \%$ emission reduction scenarios } \\
\hline & GLO & NAM & EUR & SAS & EAS & MDE & RBU & PIN & TRN & RES \\
\hline CAM-Chem & 34,000 & 800 & 0 & 12,400 & 3,600 & -700 & $-1,300$ & --- & --- & --- \\
\hline CHASER_T42 & 64,900 & 4,000 & 2,800 & 23,800 & 22,000 & 900 & 1,100 & 27,800 & 23,400 & 9,600 \\
\hline CHASER_T106 & 58,700 & 3,500 & 2,500 & 23,000 & 19,300 & --- & --- & --- & --- & --- \\
\hline C-IFS & 32,100 & 1,600 & 400 & 16,400 & 5,200 & --- & --- & --- & --- & --- \\
\hline EMEPrv48 & 52,600 & 3,500 & 2,300 & 20,400 & 14,200 & 1,200 & 2,100 & --- & --- & --- \\
\hline $\begin{array}{l}\text { GEOSCHEMADJ } \\
\text { OINT }\end{array}$ & 37,600 & 2,600 & 900 & 15,100 & 7,800 & 1,000 & 500 & 13,200 & 14,400 & 8,500 \\
\hline GEOS-Chem & 40,600 & 3,100 & --- & --- & 12,100 & --- & --- & --- & --- & --- \\
\hline GFDL_AM3 & 50,300 & 3,200 & 2,600 & --- & 9,200 & --- & --- & --- & --- & --- \\
\hline HadGEM2-ES & 54,700 & 3,300 & 2,600 & 28,600 & 9,700 & 1,100 & 1,200 & 17,000 & 21,002 & 15,100 \\
\hline OsloCTM3.v2 & 46,700 & 2,200 & 1,400 & 19,100 & 12,100 & 1,600 & 400 & 18,600 & 16,000 & 8,300 \\
\hline RAQMS & --- & --- & --- & --- & 8,600 & --- & --- & --- & --- & --- \\
\hline $\begin{array}{l}\text { Multi-model } \\
\text { mean }\end{array}$ & $47,200 \pm 10,400$ & $2,800 \pm 900$ & $1,700 \pm 1,000$ & $19,800 \pm 4,900$ & $11,200 \pm 5,300$ & $800 \pm 700$ & $600 \pm 1,000$ & $19,200 \pm 5,300$ & $18,800 \pm 3,600$ & $10,400 \pm 2,800$ \\
\hline
\end{tabular}


Table S10 -Global avoided PM2.5-related mortality (IHD+Stroke+COPD+LC) in 20\% emission reduction scenarios for the year 2010, showing the deterministic mean. All numbers are rounded to three significant figures or the nearest 100 deaths.

\begin{tabular}{|c|c|c|c|c|c|c|c|c|c|c|}
\hline \multirow{2}{*}{ Models } & \multicolumn{10}{|c|}{$20 \%$ emission reduction scenarios } \\
\hline & GLO & NAM & EUR & SAS & EAS & MDE & RBU & PIN & TRN & RES \\
\hline CHASER_T42 & 375,000 & 27,100 & 57,500 & 57,800 & 116,000 & 11,500 & 25,800 & 179,000 & 44,000 & 86,500 \\
\hline CHASER_T106 & 375,000 & 26,200 & 60,500 & 54,900 & 111,000 & --- & --- & --- & --- & --- \\
\hline C-IFS & 172,000 & 5,900 & 8,100 & 27,500 & 86,300 & --- & --- & --- & --- & --- \\
\hline EMEPrv48 & 375,000 & 21,200 & 55,900 & 57,800 & 113,000 & 3,500 & 33,400 & --- & --- & --- \\
\hline GEOSCHEMADJOINT & 435,000 & 29,000 & 71,000 & 84,300 & 126,000 & 16,100 & 39,000 & 140,000 & 66,000 & 78,900 \\
\hline GOCART & 231,000 & 15,200 & 19,600 & 46,000 & 89,600 & 2,500 & 15,000 & 114,000 & 10,300 & 98,100 \\
\hline SPRINTARS & 225,000 & 10,900 & 13,200 & 50,000 & 95,600 & 4,500 & 5,600 & 122,000 & 7,800 & 89,500 \\
\hline Multi-model mean & $307,000 \pm 88,500$ & $20,600 \pm 7,700$ & $40,500 \pm 23,000$ & $57,000 \pm 14,800$ & $106,000 \pm 13,400$ & $6,700 \pm 5,200$ & $22,100 \pm 11,700$ & $139,000 \pm 25,100$ & $32,000 \pm 24,200$ & $88,200 \pm 6,900$ \\
\hline
\end{tabular}


Table $\mathrm{S}_{11} \mathrm{O}_{3}$-related deaths in regional reduction scenarios, including the deterministic means, results from the Monte Carlo analysis, and analysis of uncertainty showing the standard deviation and coefficient of variation (\%) due to uncertainties from the spread of individual model results, the relative risks (RRs), and baseline mortality rates.

\begin{tabular}{|c|c|c|c|c|c|c|c|c|c|c|c|c|c|}
\hline & & \multicolumn{3}{|c|}{ Spread of model } & \multicolumn{3}{|c|}{ RRs } & \multicolumn{3}{|c|}{ Baseline rates } & \multicolumn{3}{|c|}{ Monte-Carlo analysis } \\
\hline source & Receptor & mean & stdev & $\mathrm{CV}$ & mean & stdev & $\mathrm{CV}$ & mean & stdev & $\mathrm{CV}$ & mean & $2.5 \%$ & $97.5 \%$ \\
\hline \multirow{6}{*}{ NAM } & NAM & 1,516 & 699 & $46 \%$ & 1,516 & 510 & $34 \%$ & 1,516 & 154 & $10 \%$ & 1,529 & -169 & 4,037 \\
\hline & ERU & 325 & 98 & $30 \%$ & 325 & 108 & $33 \%$ & 325 & 38 & $12 \%$ & 327 & -11 & -797 \\
\hline & SAS & 165 & 701 & $425 \%$ & 165 & 55 & $34 \%$ & 165 & 27 & $17 \%$ & 172 & -246 & -685 \\
\hline & EAS & 509 & 262 & $52 \%$ & 509 & 170 & $33 \%$ & 509 & 45 & $9 \%$ & 527 & -910 & 2,209 \\
\hline & MDE & 32 & 10 & $31 \%$ & 32 & 11 & $33 \%$ & 32 & 6 & $18 \%$ & 33 & 2 & 82 \\
\hline & RBU & 66 & 20 & $31 \%$ & 66 & 22 & $33 \%$ & 66 & 8 & $12 \%$ & 66 & -2 & 168 \\
\hline \multirow{6}{*}{ EUR } & NAM & 61 & 36 & $58 \%$ & 61 & 20 & $33 \%$ & 61 & 6 & $10 \%$ & 63 & -81 & 239 \\
\hline & ERU & 919 & 727 & $79 \%$ & 919 & 308 & $34 \%$ & 919 & 111 & $12 \%$ & 929 & -73 & 2,440 \\
\hline & SAS & -68 & 728 & $1065 \%$ & -68 & -23 & $33 \%$ & -68 & -10 & $14 \%$ & -80 & -875 & 668 \\
\hline & EAS & 471 & 309 & $66 \%$ & 471 & 157 & $33 \%$ & 471 & 40 & $9 \%$ & 492 & $-1,052$ & 2,260 \\
\hline & MDE & 45 & 11 & $25 \%$ & 45 & 15 & $33 \%$ & 45 & 8 & $18 \%$ & 45 & 6 & 107 \\
\hline & RBU & 107 & 31 & $29 \%$ & 107 & 36 & $33 \%$ & 107 & 13 & $12 \%$ & 108 & 7 & 253 \\
\hline \multirow{6}{*}{ SAS } & NAM & 36 & 18 & $49 \%$ & 36 & 12 & $33 \%$ & 36 & 4 & $10 \%$ & 37 & -39 & 133 \\
\hline & ERU & 50 & 28 & $56 \%$ & 50 & 17 & $33 \%$ & 50 & 6 & $12 \%$ & 51 & -31 & 157 \\
\hline & SAS & 18,864 & 5,202 & $28 \%$ & 18,864 & 6,378 & $34 \%$ & 18,864 & 2,968 & $16 \%$ & 19,013 & 4,000 & 42,201 \\
\hline & EAS & 408 & 215 & $53 \%$ & 408 & 136 & $33 \%$ & 408 & 34 & $8 \%$ & 416 & -339 & 1,373 \\
\hline & MDE & 15 & 6 & $39 \%$ & 15 & 5 & $33 \%$ & 15 & 3 & $19 \%$ & 15 & 0 & 41 \\
\hline & RBU & 13 & 9 & $68 \%$ & 13 & 4 & $33 \%$ & 13 & 2 & $12 \%$ & 13 & -7 & 40 \\
\hline \multirow{6}{*}{ EAS } & NAM & 228 & 121 & $53 \%$ & 228 & 76 & $33 \%$ & 228 & 23 & $10 \%$ & 230 & -51 & 629 \\
\hline & ERU & 311 & 163 & $52 \%$ & 311 & 104 & $33 \%$ & 311 & 36 & $12 \%$ & 314 & -54 & 848 \\
\hline & SAS & 423 & 828 & $196 \%$ & 423 & 141 & $33 \%$ & 423 & 68 & $16 \%$ & 449 & $-1,249$ & 2,381 \\
\hline & EAS & 9,609 & 5,254 & $55 \%$ & 9,609 & 3,241 & $34 \%$ & 9,609 & 813 & $8 \%$ & 9,696 & $-2,015$ & 26,364 \\
\hline & MDE & 33 & 15 & $45 \%$ & 33 & 11 & $33 \%$ & 33 & 6 & $18 \%$ & 34 & -3 & 95 \\
\hline & RBU & 84 & 38 & $46 \%$ & 84 & 28 & $33 \%$ & 84 & 10 & $12 \%$ & 84 & -10 & 225 \\
\hline \multirow{6}{*}{ MDE } & NAM & 34 & 19 & $56 \%$ & 34 & 11 & $33 \%$ & 34 & 3 & $10 \%$ & 34 & -33 & 121 \\
\hline & ERU & 55 & 17 & $31 \%$ & 55 & 18 & $33 \%$ & 55 & 7 & $13 \%$ & 57 & -45 & 187 \\
\hline & SAS & 304 & 845 & $278 \%$ & 304 & 102 & $33 \%$ & 304 & 50 & $16 \%$ & 310 & -89 & 911 \\
\hline & EAS & 158 & 70 & $45 \%$ & 158 & 53 & $33 \%$ & 158 & 14 & $9 \%$ & 160 & -117 & 520 \\
\hline & MDE & 172 & 97 & $57 \%$ & 172 & 58 & $34 \%$ & 172 & 31 & $18 \%$ & 176 & -6 & 479 \\
\hline & RBU & 30 & 4 & $13 \%$ & 30 & 10 & $33 \%$ & 30 & 4 & $13 \%$ & 30 & 1 & 74 \\
\hline \multirow{6}{*}{ RBU } & NAM & 41 & 34 & $82 \%$ & 41 & 14 & $33 \%$ & 41 & 4 & $10 \%$ & 42 & -60 & 166 \\
\hline & ERU & 152 & 69 & $46 \%$ & 152 & 51 & $33 \%$ & 152 & 19 & $12 \%$ & 154 & -45 & 440 \\
\hline & SAS & -178 & 850 & $478 \%$ & -178 & -59 & $33 \%$ & -178 & -28 & $16 \%$ & -199 & $-1,707$ & 1,175 \\
\hline & EAS & 407 & 332 & $82 \%$ & 407 & 136 & $33 \%$ & 407 & 35 & $9 \%$ & 420 & -622 & 1,660 \\
\hline & MDE & 16 & 12 & $73 \%$ & 16 & 5 & $33 \%$ & 16 & 3 & $17 \%$ & 17 & -12 & 56 \\
\hline & RBU & 139 & 129 & $93 \%$ & 139 & 47 & $34 \%$ & 139 & 17 & $12 \%$ & 141 & -63 & 422 \\
\hline
\end{tabular}


Table S12 $\mathrm{PM}_{2.5}$-related deaths in regional reduction scenarios, including the deterministic means, results from the Monte Carlo analysis, and analysis of uncertainty showing the standard deviation and coefficient of variation (\%) due to uncertainties from the spread of individual model results, the relative risks (RRs), and baseline mortality rates.

\begin{tabular}{|c|c|c|c|c|c|c|c|c|c|c|c|c|c|}
\hline \multirow[b]{2}{*}{ source } & \multirow[b]{2}{*}{ Receptor } & \multicolumn{3}{|c|}{ Spread of model } & \multicolumn{3}{|c|}{ RRs } & \multicolumn{3}{|c|}{ Baseline Mortaltiy } & \multicolumn{3}{|c|}{ Monte-Carlo analysis } \\
\hline & & mean & stdev & $\mathrm{Cv}$ & mean & stdev & $\mathrm{CV}$ & mean & stdev & $\mathrm{CV}$ & mean & $2.5 \%$ & $97.5 \%$ \\
\hline \multirow{6}{*}{ NAM } & NAM & 17,686 & 7,015 & $40 \%$ & 17,686 & 3,071 & $17 \%$ & 17,686 & 1,819 & $10 \%$ & 17,988 & 630 & 28,310 \\
\hline & ERU & 629 & 711 & $113 \%$ & 629 & 68 & $11 \%$ & 629 & 60 & $9 \%$ & 640 & 82 & 1,076 \\
\hline & SAS & -11 & 193 & $1682 \%$ & -11 & 5 & $46 \%$ & -11 & -1 & $6 \%$ & 11 & -207 & 82 \\
\hline & EAS & 214 & 250 & $117 \%$ & 214 & -2 & $1 \%$ & 214 & 21 & $10 \%$ & 196 & -296 & 365 \\
\hline & MDE & 9 & 52 & $579 \%$ & 9 & 2 & $21 \%$ & 9 & 1 & $16 \%$ & 8 & -5 & 28 \\
\hline & RBU & 298 & 387 & $130 \%$ & 298 & 32 & $11 \%$ & 298 & 16 & $5 \%$ & 250 & 89 & 420 \\
\hline \multirow{6}{*}{ EUR } & NAM & 62 & 34 & $55 \%$ & 62 & 18 & $30 \%$ & 62 & 6 & $10 \%$ & 62 & 6 & 108 \\
\hline & ERU & 31,072 & 19,747 & $64 \%$ & 31,072 & 4,560 & $15 \%$ & 31,072 & 2,785 & $9 \%$ & 31,924 & 4,521 & 53,853 \\
\hline & SAS & 123 & 140 & $113 \%$ & 123 & 19 & $15 \%$ & 123 & 22 & $18 \%$ & 117 & -57 & 188 \\
\hline & EAS & 412 & 182 & $44 \%$ & 412 & 20 & $5 \%$ & 412 & 40 & $10 \%$ & 389 & -23 & 550 \\
\hline & MDE & 537 & 448 & $83 \%$ & 537 & -16 & $3 \%$ & 537 & 68 & $13 \%$ & 401 & 27 & 1,363 \\
\hline & RBU & 5,826 & 3,940 & $68 \%$ & 5,826 & 476 & $8 \%$ & 5,826 & 317 & $5 \%$ & 5,743 & 681 & 8,033 \\
\hline \multirow{6}{*}{ SAS } & NAM & 46 & 65 & $142 \%$ & 46 & 15 & $32 \%$ & 46 & 5 & $10 \%$ & 46 & -14 & 88 \\
\hline & ERU & 109 & 111 & $102 \%$ & 109 & 2 & $2 \%$ & 109 & 10 & $10 \%$ & 113 & 14 & 196 \\
\hline & SAS & 50,435 & 14,936 & $30 \%$ & 50,435 & 5,748 & $11 \%$ & 50,435 & 7,484 & $15 \%$ & 47,923 & 30,035 & 68,484 \\
\hline & EAS & 1,415 & 1,196 & $85 \%$ & 1,415 & 147 & $10 \%$ & 1,415 & 124 & $9 \%$ & 1,394 & -71 & 2,045 \\
\hline & MDE & 58 & 78 & $135 \%$ & 58 & 9 & $15 \%$ & 58 & 11 & $20 \%$ & 38 & 2 & 148 \\
\hline & RBU & 50 & 95 & $190 \%$ & 50 & -8 & $15 \%$ & 50 & 2 & $5 \%$ & 42 & 8 & 108 \\
\hline \multirow{6}{*}{ EAS } & NAM & 338 & 179 & $53 \%$ & 338 & 93 & $28 \%$ & 338 & 35 & $10 \%$ & 335 & 35 & 505 \\
\hline & ERU & 395 & 324 & $82 \%$ & 395 & 46 & $12 \%$ & 395 & 37 & $9 \%$ & 394 & 24 & 694 \\
\hline & SAS & 903 & 870 & $96 \%$ & 903 & 152 & $17 \%$ & 903 & 136 & $15 \%$ & 897 & 589 & 1,355 \\
\hline & EAS & 98,495 & 13,602 & $14 \%$ & 98,495 & 6,963 & $7 \%$ & 98,495 & 8,770 & $9 \%$ & 91,114 & 436 & 128,649 \\
\hline & MDE & 11 & 28 & $260 \%$ & 11 & -1 & $7 \%$ & 11 & 1 & $12 \%$ & 5 & -1 & 25 \\
\hline & RBU & 813 & 534 & $66 \%$ & 813 & 135 & $17 \%$ & 813 & 46 & $6 \%$ & 803 & 14 & 1,298 \\
\hline \multirow{6}{*}{ MDE } & NAM & 36 & 24 & $66 \%$ & 36 & 12 & $34 \%$ & 36 & 4 & $10 \%$ & 34 & -1 & 57 \\
\hline & ERU & 481 & 360 & $75 \%$ & 481 & 6 & $1 \%$ & 481 & 48 & $10 \%$ & 419 & 93 & 854 \\
\hline & SAS & 1,400 & 709 & $51 \%$ & 1,400 & 295 & $21 \%$ & 1,400 & 234 & $17 \%$ & 1,346 & 744 & 2,371 \\
\hline & EAS & 169 & 646 & $383 \%$ & 169 & -10 & $6 \%$ & 169 & 16 & $10 \%$ & 177 & -612 & 455 \\
\hline & MDE & 2,538 & 2,800 & $110 \%$ & 2,538 & 22 & $1 \%$ & 2,538 & 336 & $13 \%$ & 1,599 & 238 & 4,535 \\
\hline & RBU & 813 & 842 & $104 \%$ & 813 & 53 & $6 \%$ & 813 & 53 & $7 \%$ & 644 & 31 & 1,605 \\
\hline \multirow{6}{*}{ RBU } & NAM & 46 & 39 & $86 \%$ & 46 & 8 & $17 \%$ & 46 & 5 & $10 \%$ & 41 & 12 & 64 \\
\hline & ERU & 2,196 & 1,099 & $50 \%$ & 2,196 & 241 & $11 \%$ & 2,196 & 174 & $8 \%$ & 2,204 & 299 & 3,695 \\
\hline & SAS & 13 & 507 & $3974 \%$ & 13 & 31 & $247 \%$ & 13 & 8 & $66 \%$ & 93 & -216 & 192 \\
\hline & EAS & 859 & 376 & $44 \%$ & 859 & 61 & $7 \%$ & 859 & 82 & $10 \%$ & 814 & 334 & 1,086 \\
\hline & MDE & 106 & 111 & $104 \%$ & 106 & 1 & $1 \%$ & 106 & 13 & $12 \%$ & 75 & 9 & 222 \\
\hline & RBU & 18,001 & 10,178 & $57 \%$ & 18,001 & 2,625 & $15 \%$ & 18,001 & 985 & $5 \%$ & 17,640 & 386 & 25,674 \\
\hline
\end{tabular}



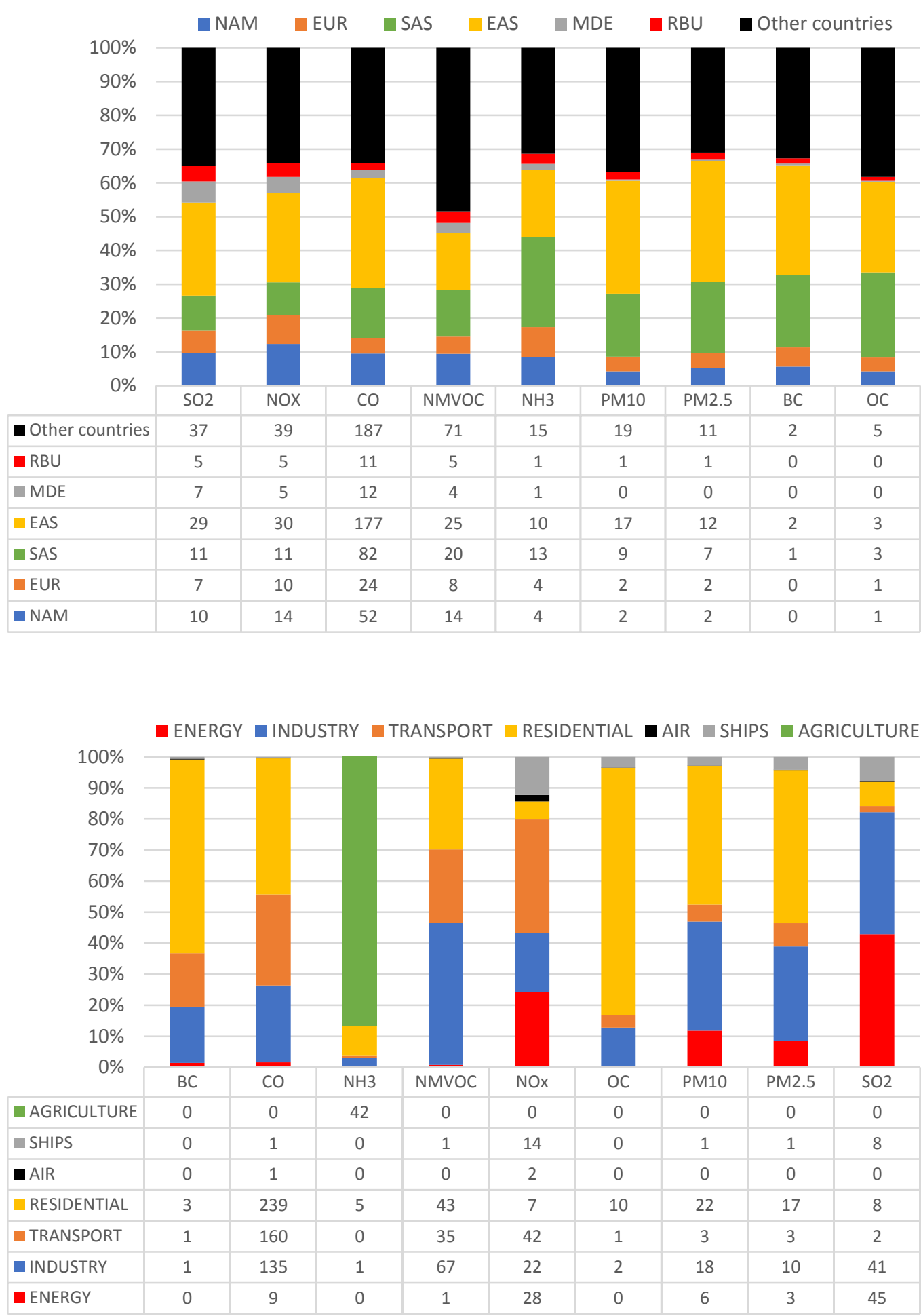

Figure S1. Regional (upper panel) and sectoral (lower panel) percent of total anthropogenic emissions of gaseous pollutants and particulate matter for the year 2010. Global absolute emissions are reported on bottom table in Tg species per year (Adapted from Janssens-Maenhout et al (2015)). 


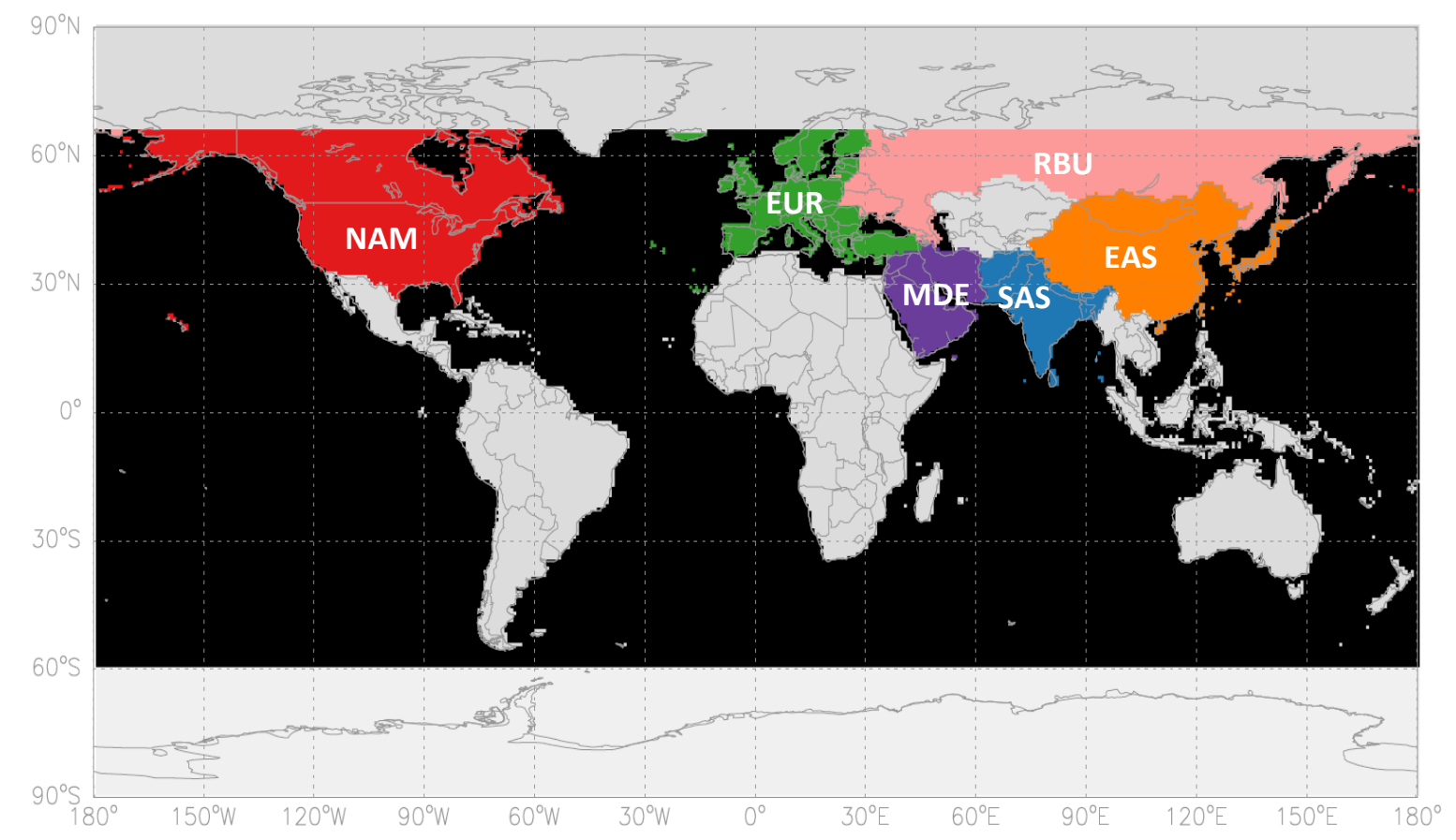

Figure S2. Six priority regions defined by TF-HTAP2 - NAM: North America, EUR: Europe, EAS: East Asia, SAS: South Asia, RBU; Russia/Belarus/Ukraine and MDE: Middle East. 

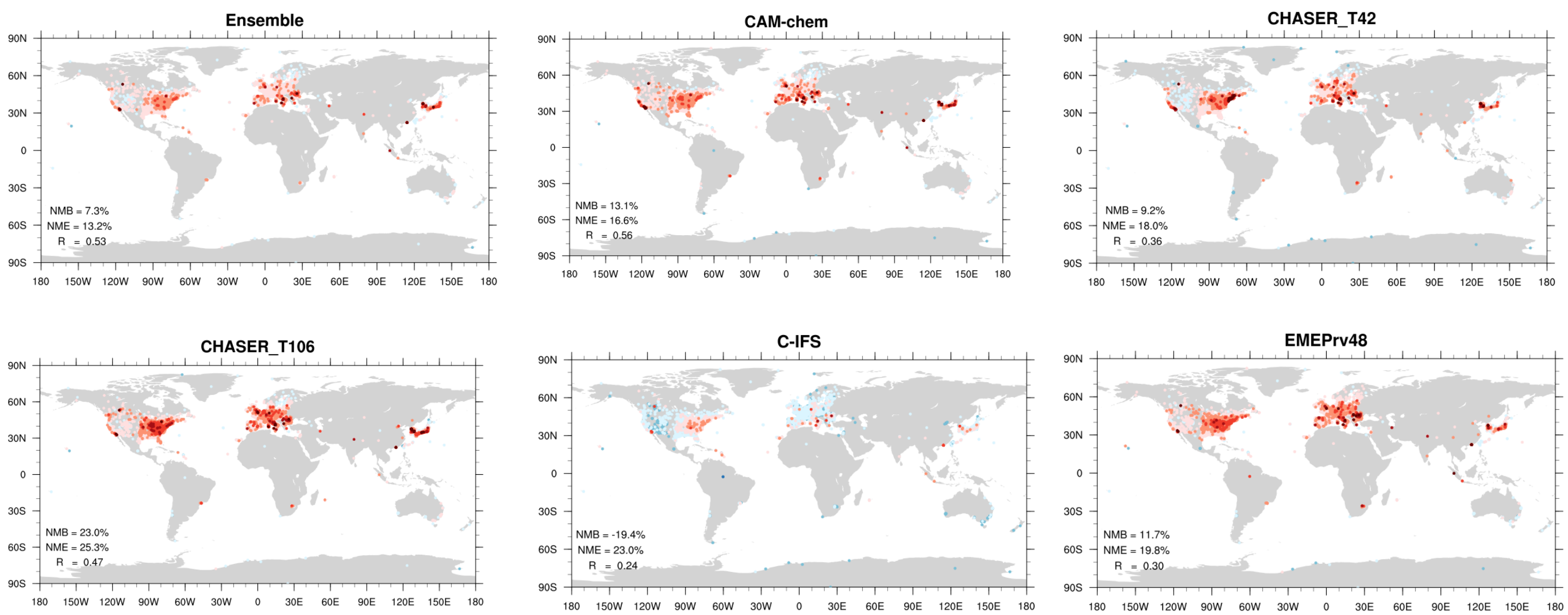

$$
\text { - } \quad x<-50 \%
$$

$$
\begin{array}{ll}
-25 \%<=x<0 \% & -25 \%<=x<50 \% \\
0 \%<=x<25 \% & -50 \%<=x<75 \%
\end{array}
$$

- $75 \%<=x<100 \%$

- $x>=100 \%$

Figure S3. Spatial distributions of model performance for the maximum 3-month average of daily 1-hour maximum $\mathrm{O}_{3}$ comparing TOAR observations with individual model simulations and the ensemble mean. The overall statistical parameters for each model are in the bottom left of each plot. 

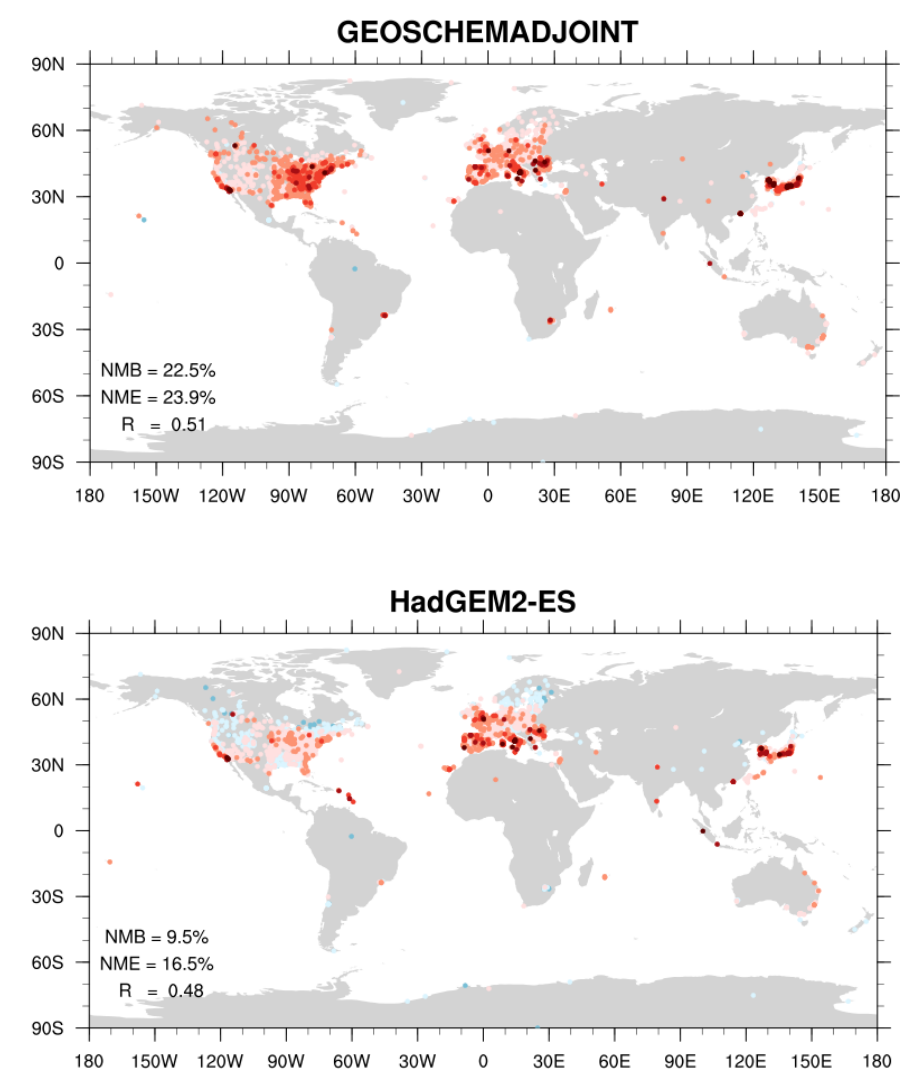

$$
\text { - } x<-50 \%
$$

- $-50 \%<=x<-25 \%$
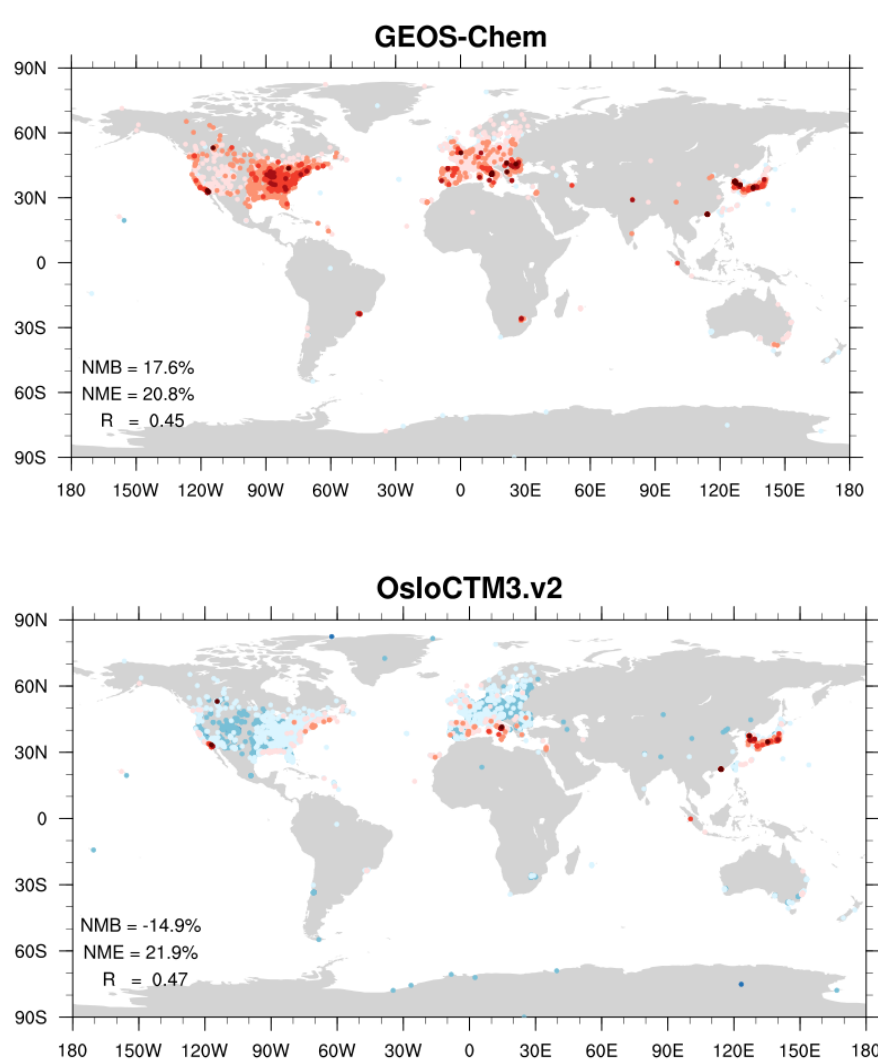

$$
\begin{array}{ll}
-25 \%<=x<0 \% & -25 \%<=x<50 \% \\
0 \%<=x<25 \% & -50 \%<=x<75 \%
\end{array}
$$
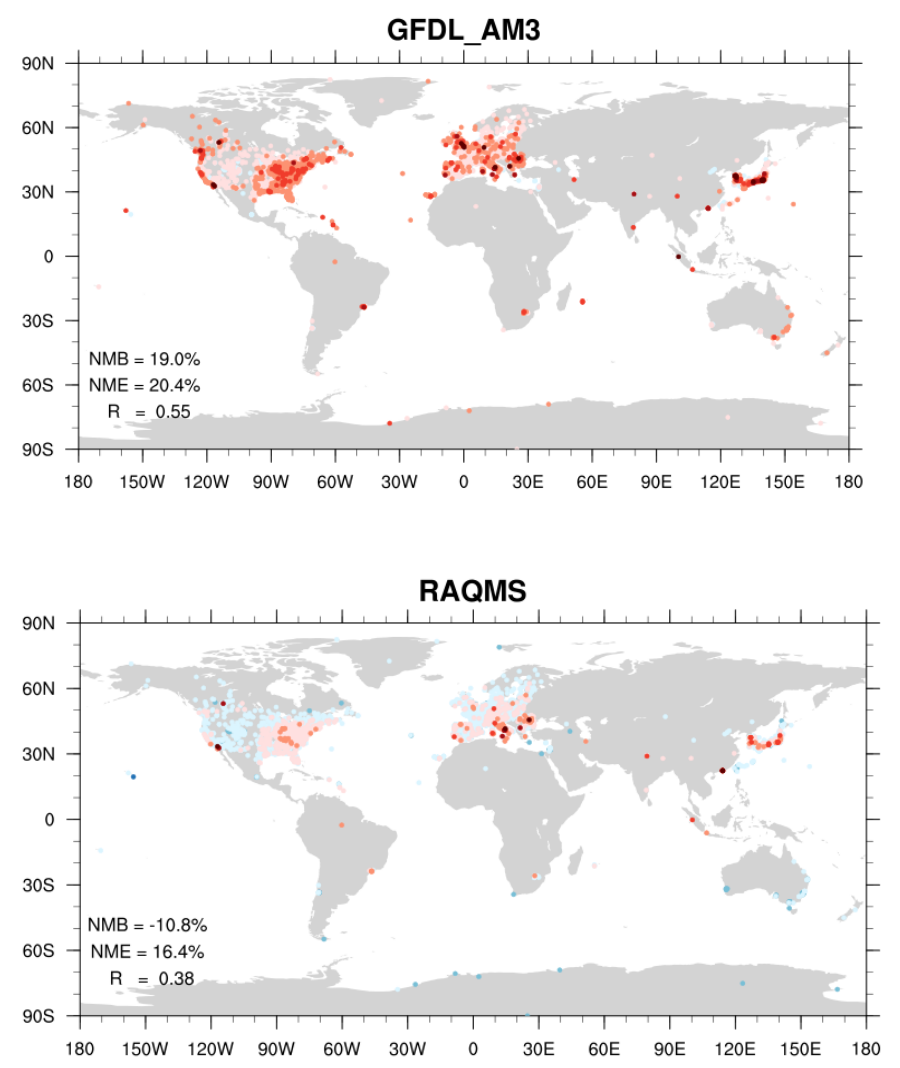

- $75 \%<=x<100 \%$

- $x>=100 \%$

Figure S3. Continued. 

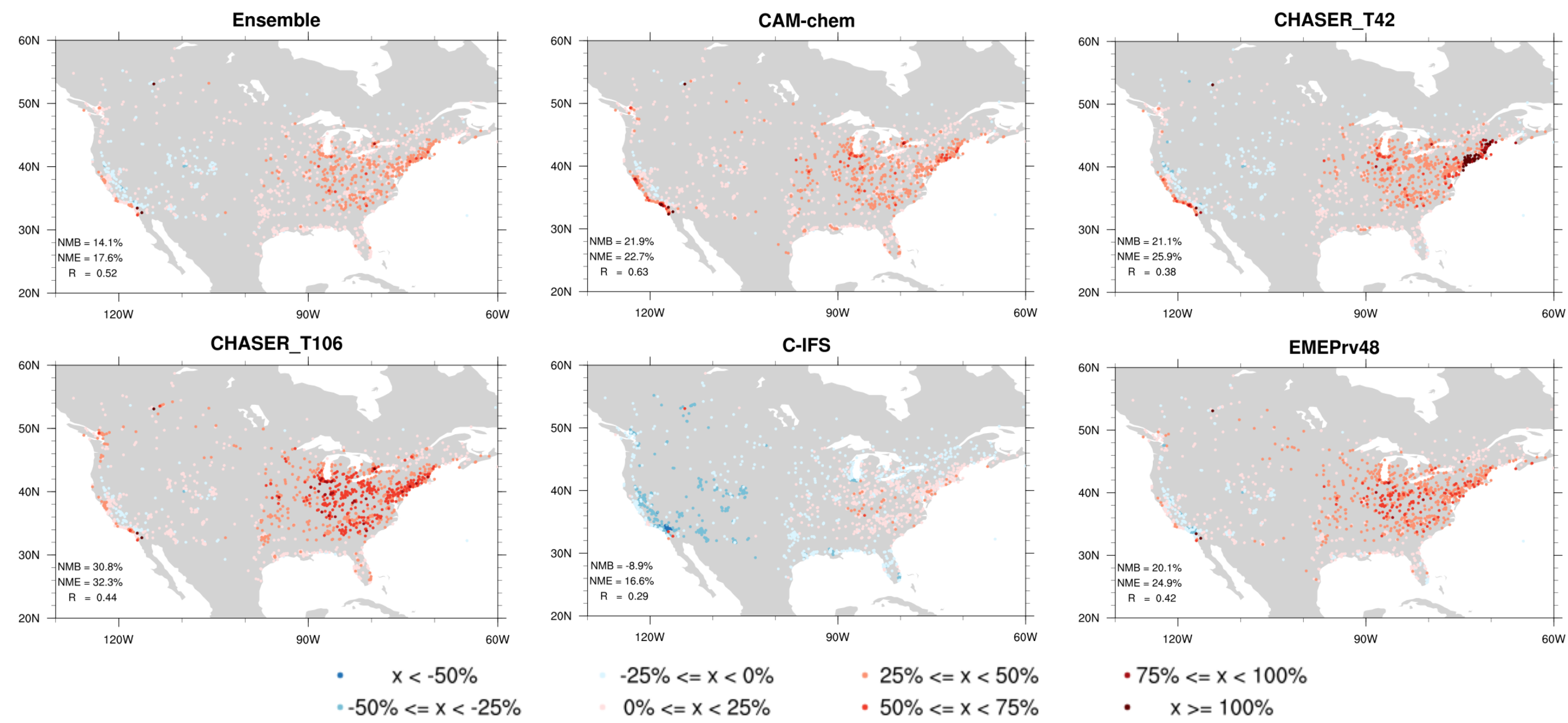

Figure S4. As Figure S3, but for North America. 

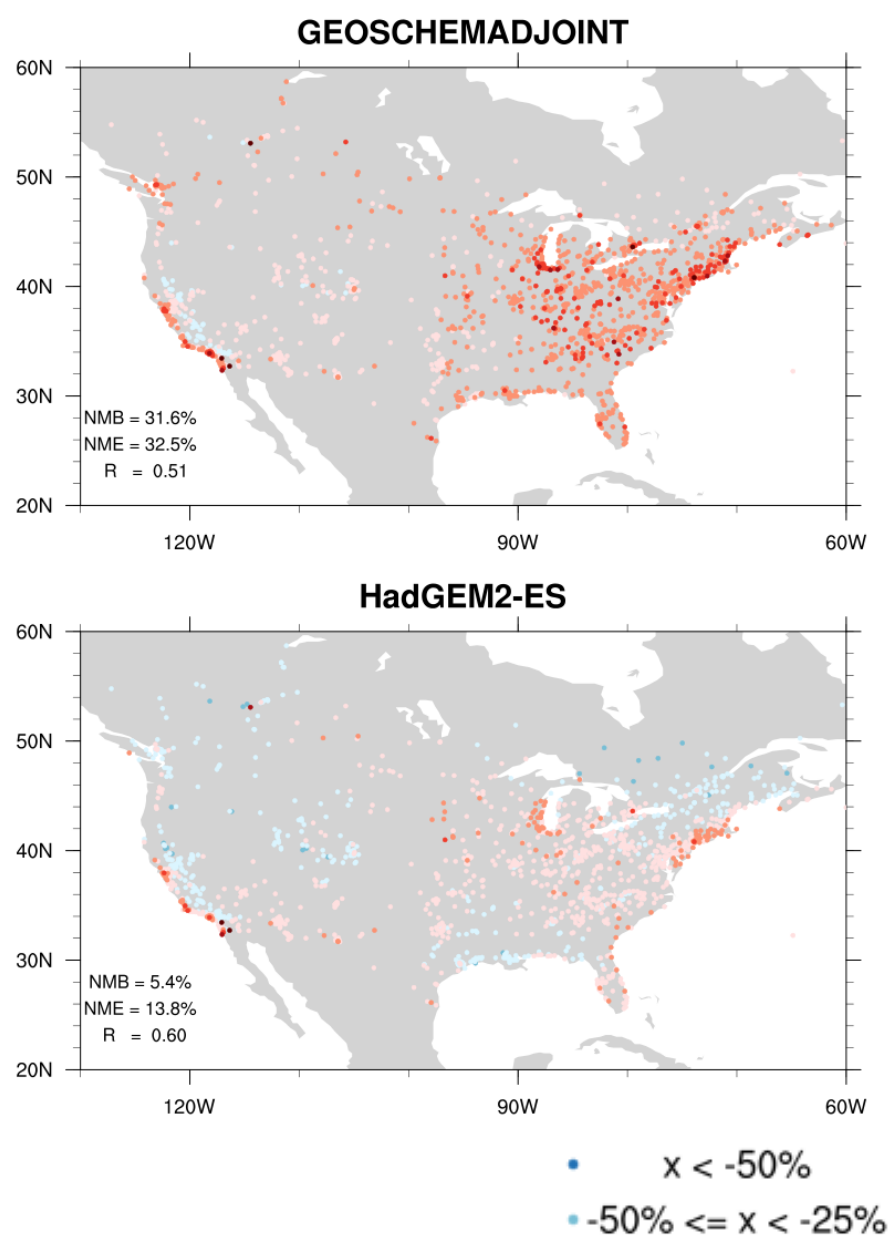

Figure S4. Continued.
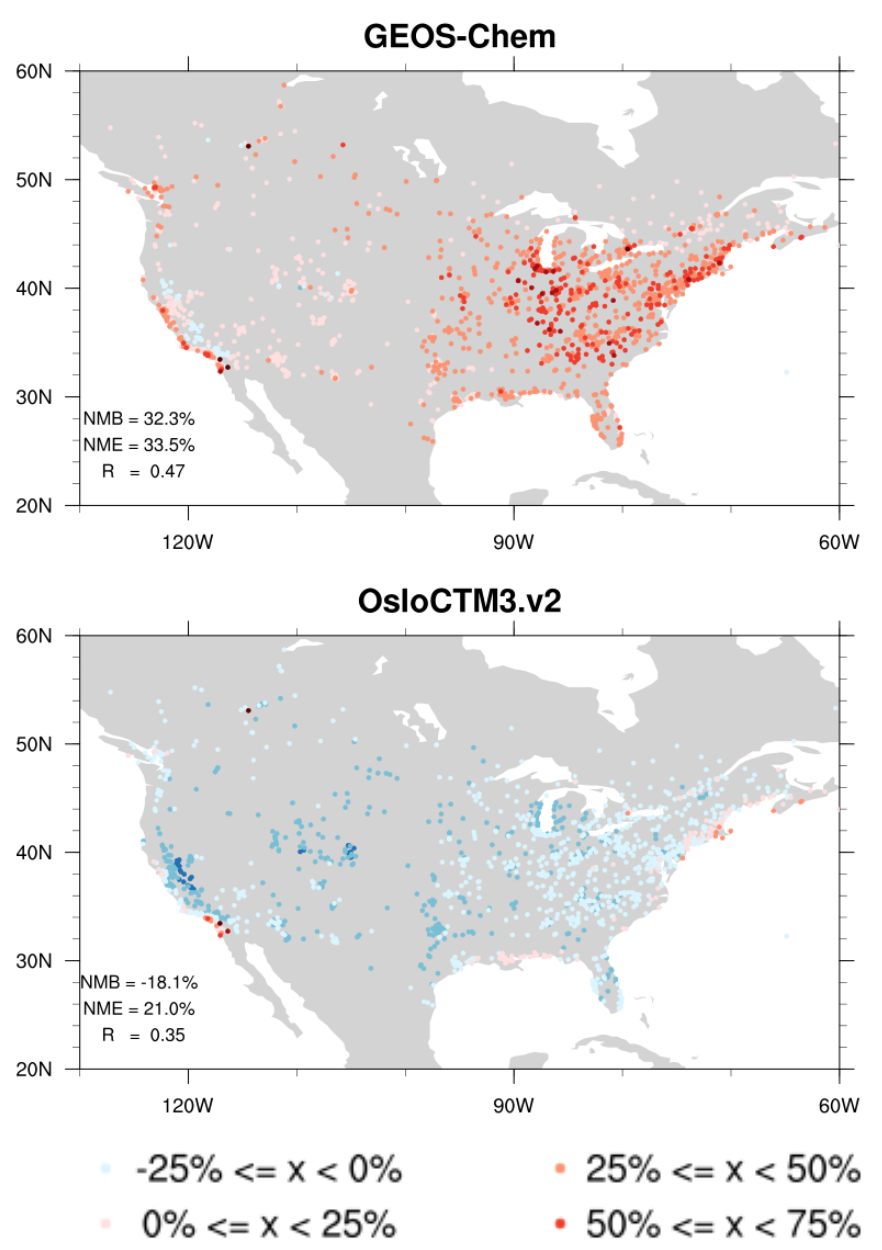

GFDL_AM3

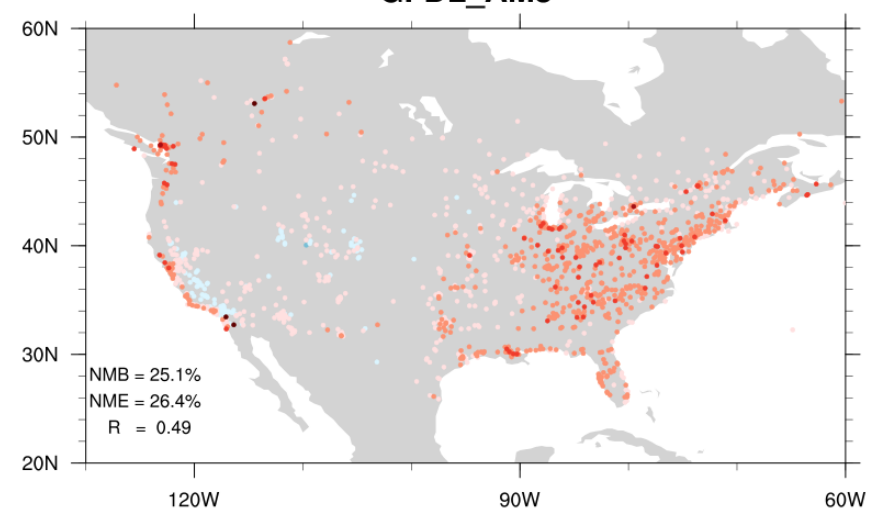

RAQMS

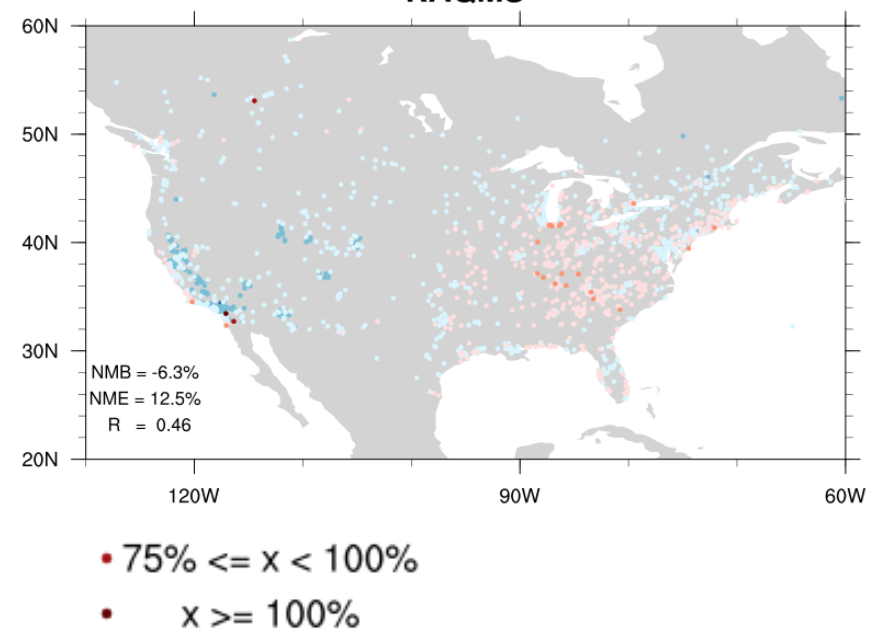



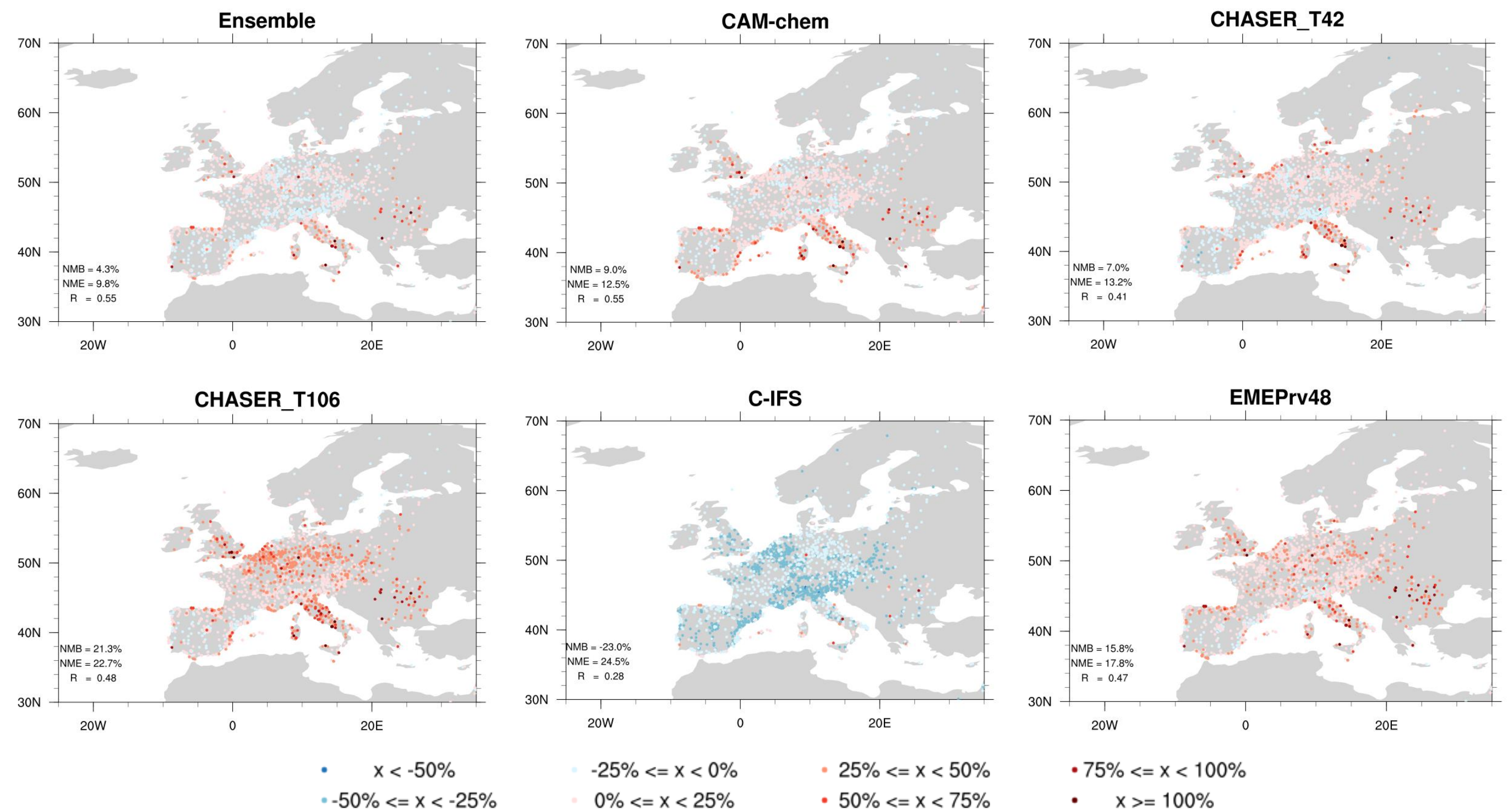

Figure S5. As Figure S3, but for Europe. 

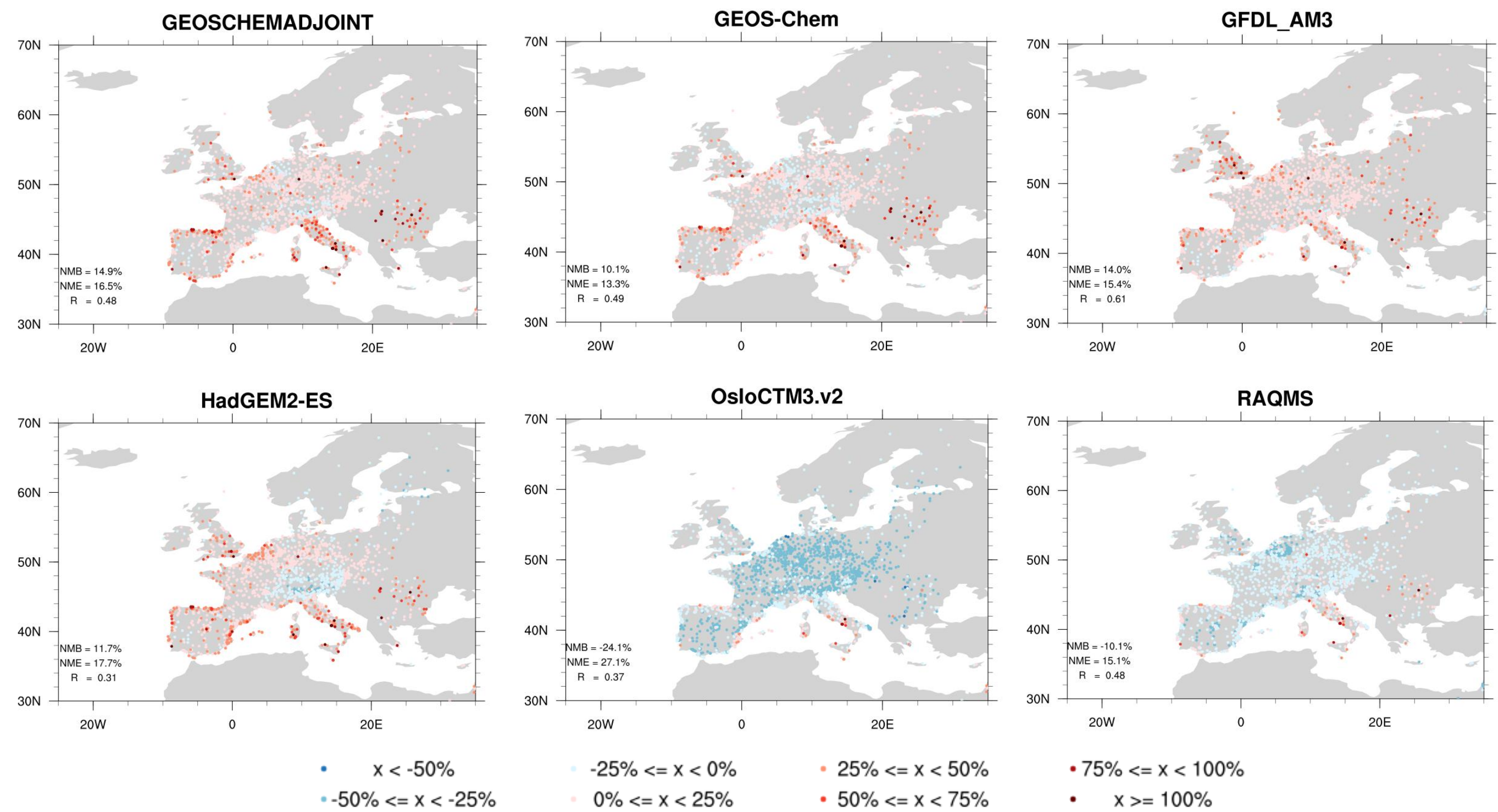

Figure S5. Continued. 

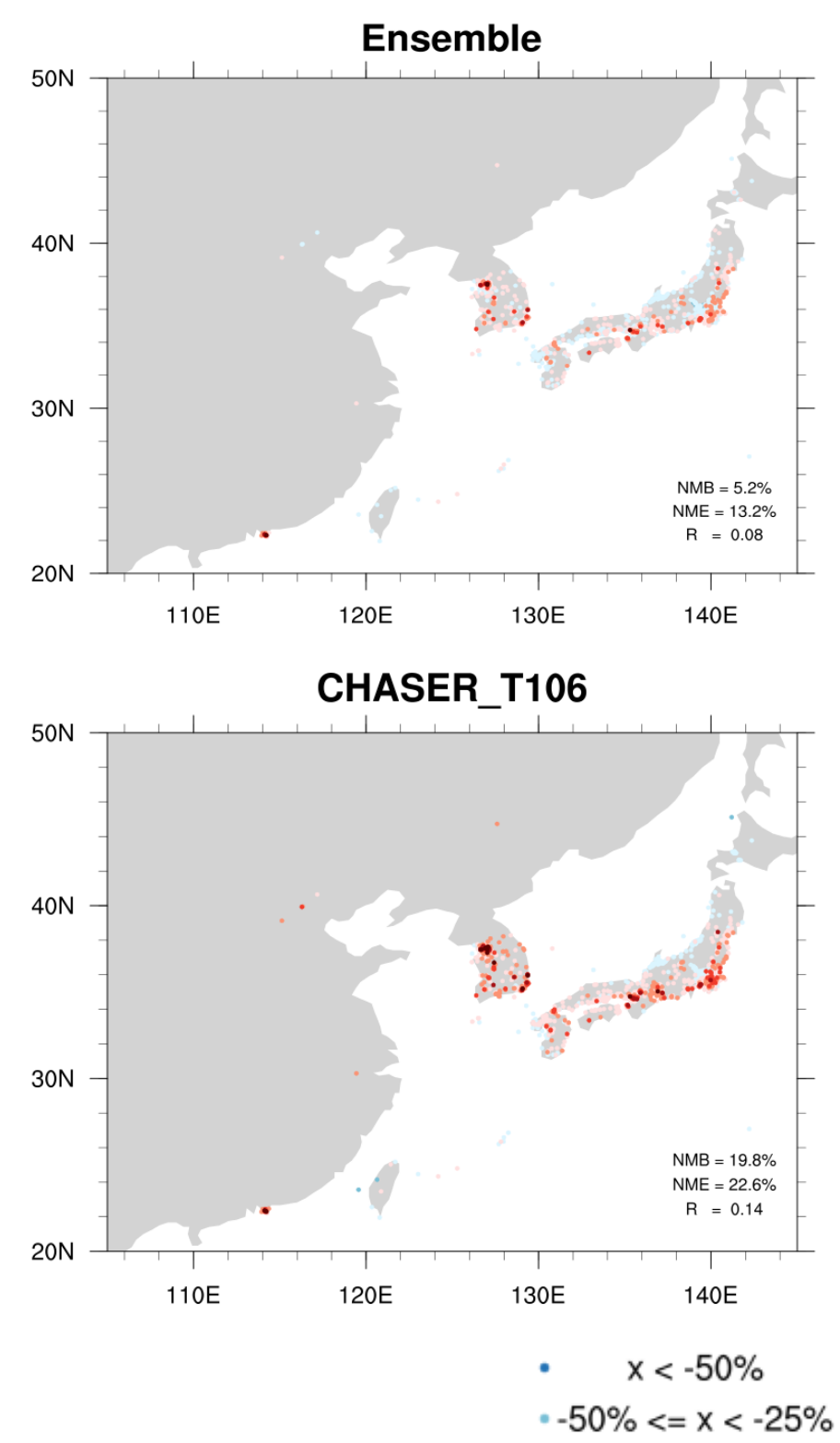

Figure S6. As Figure S3, but for East Asia.
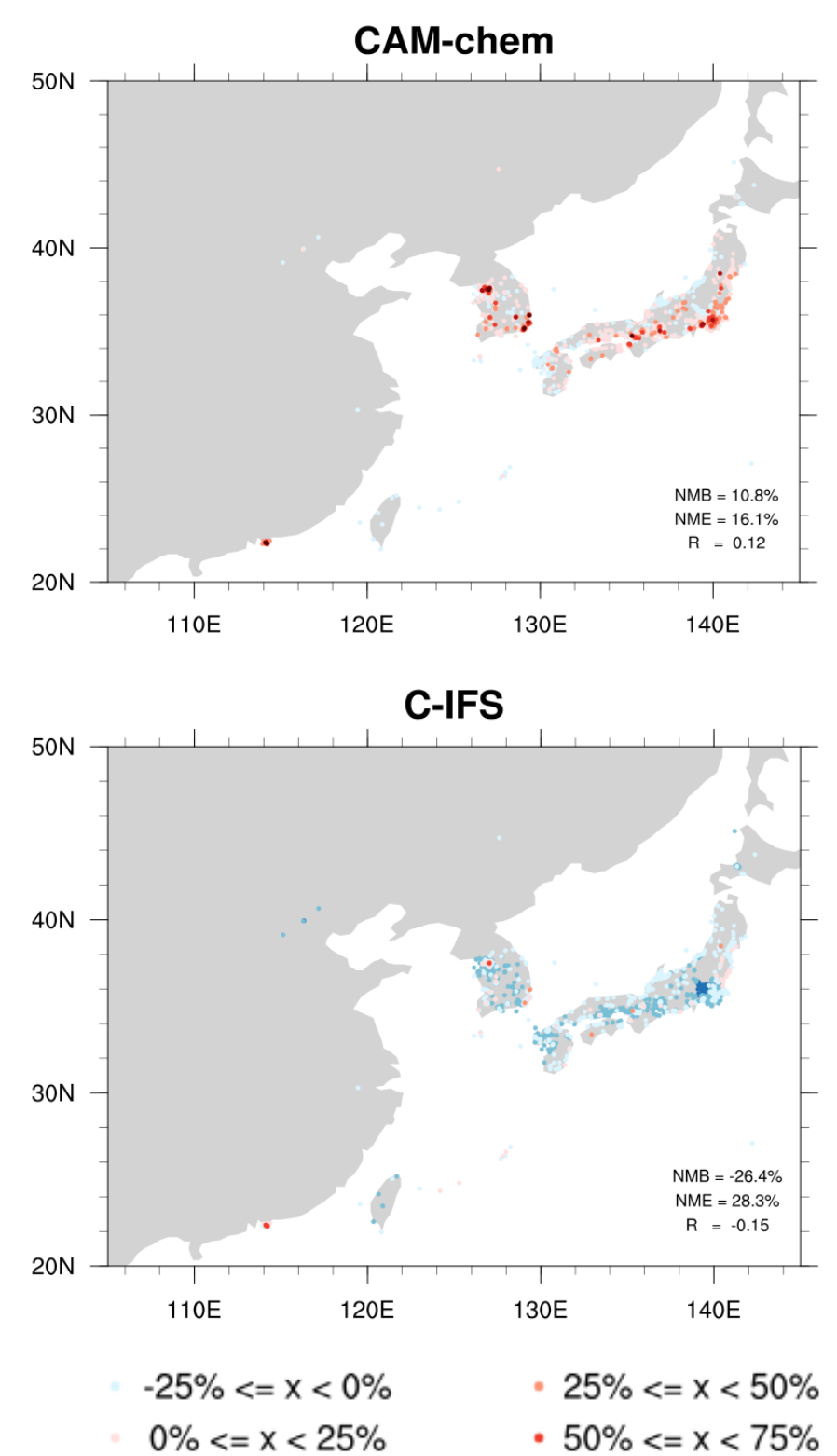
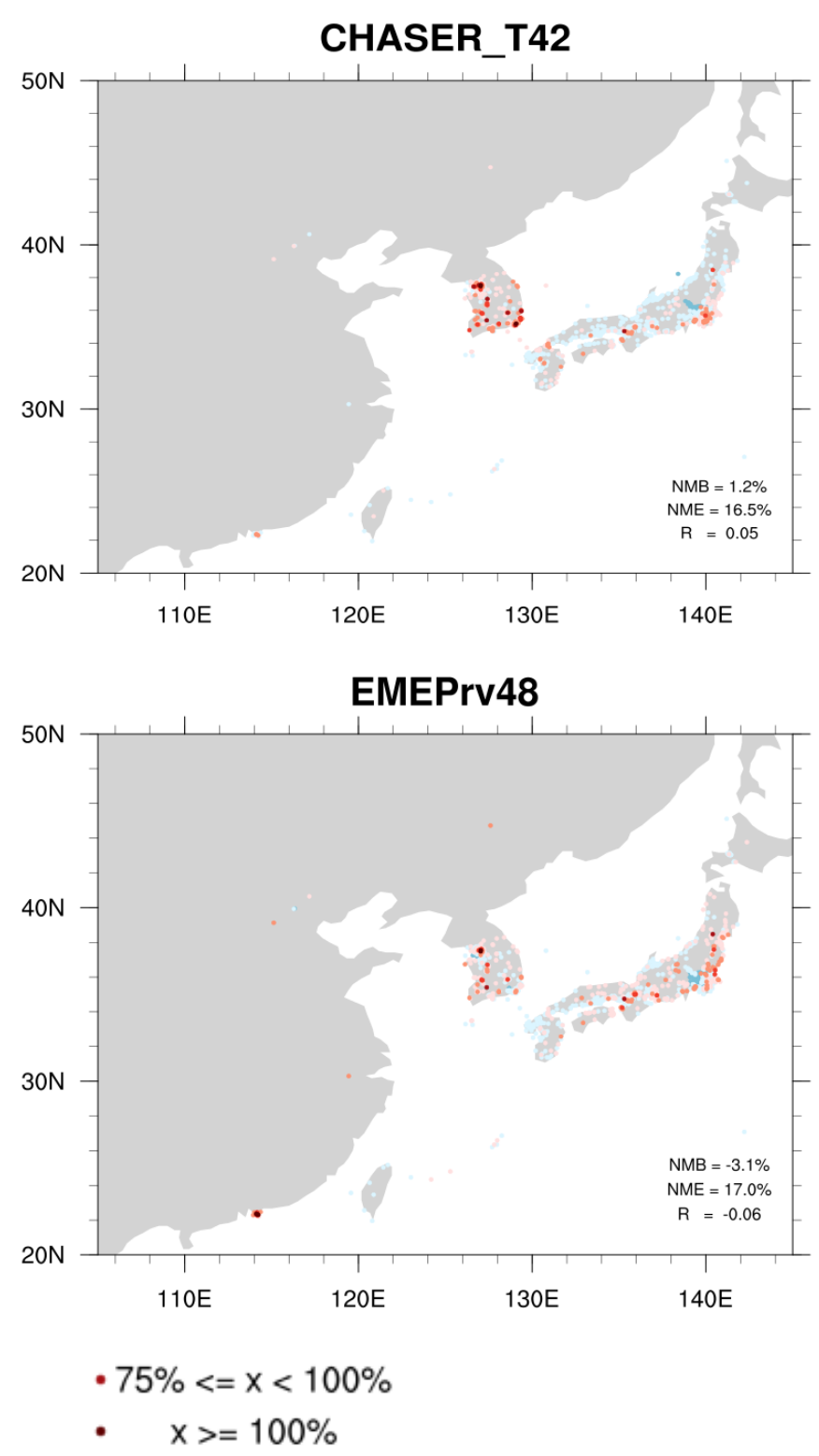


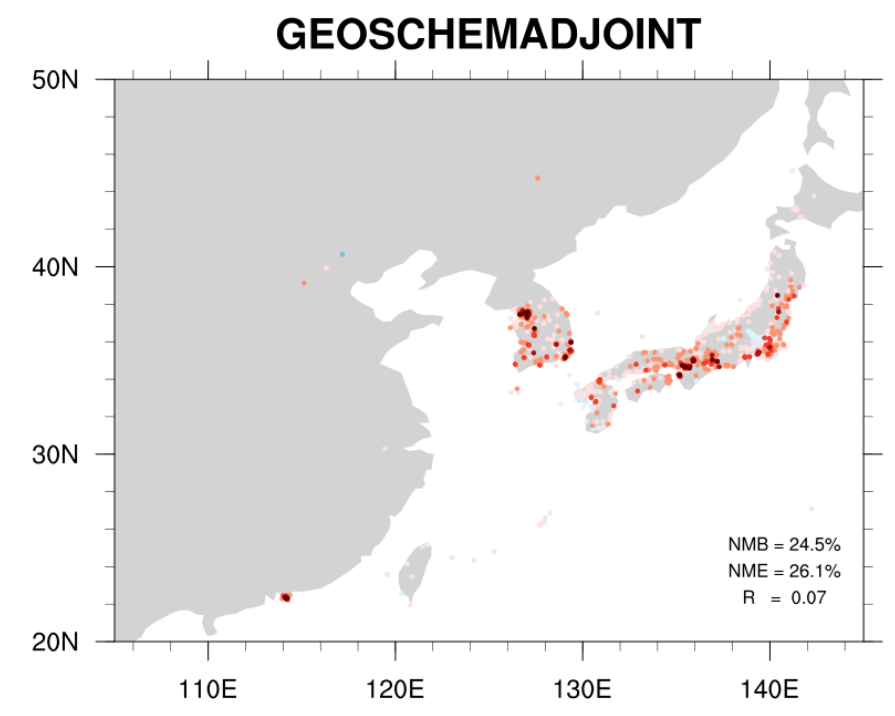

HadGEM2-ES

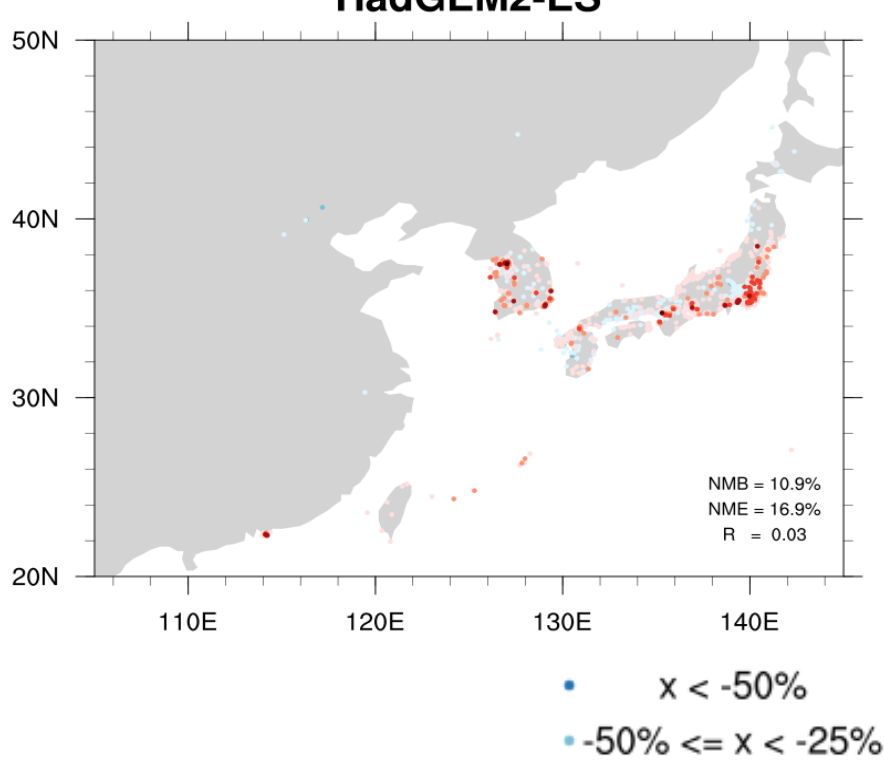

Figure S6. Continued.
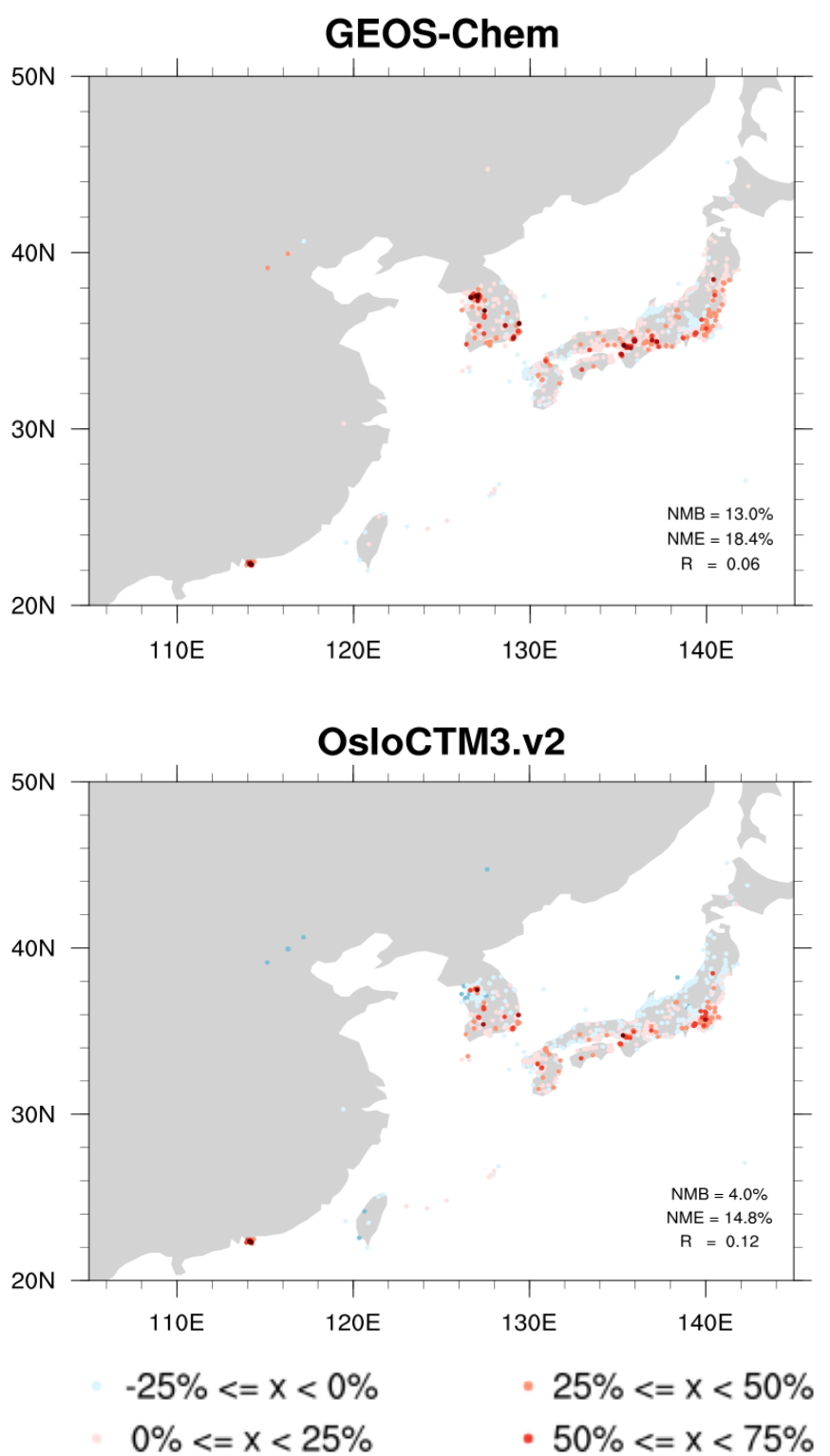
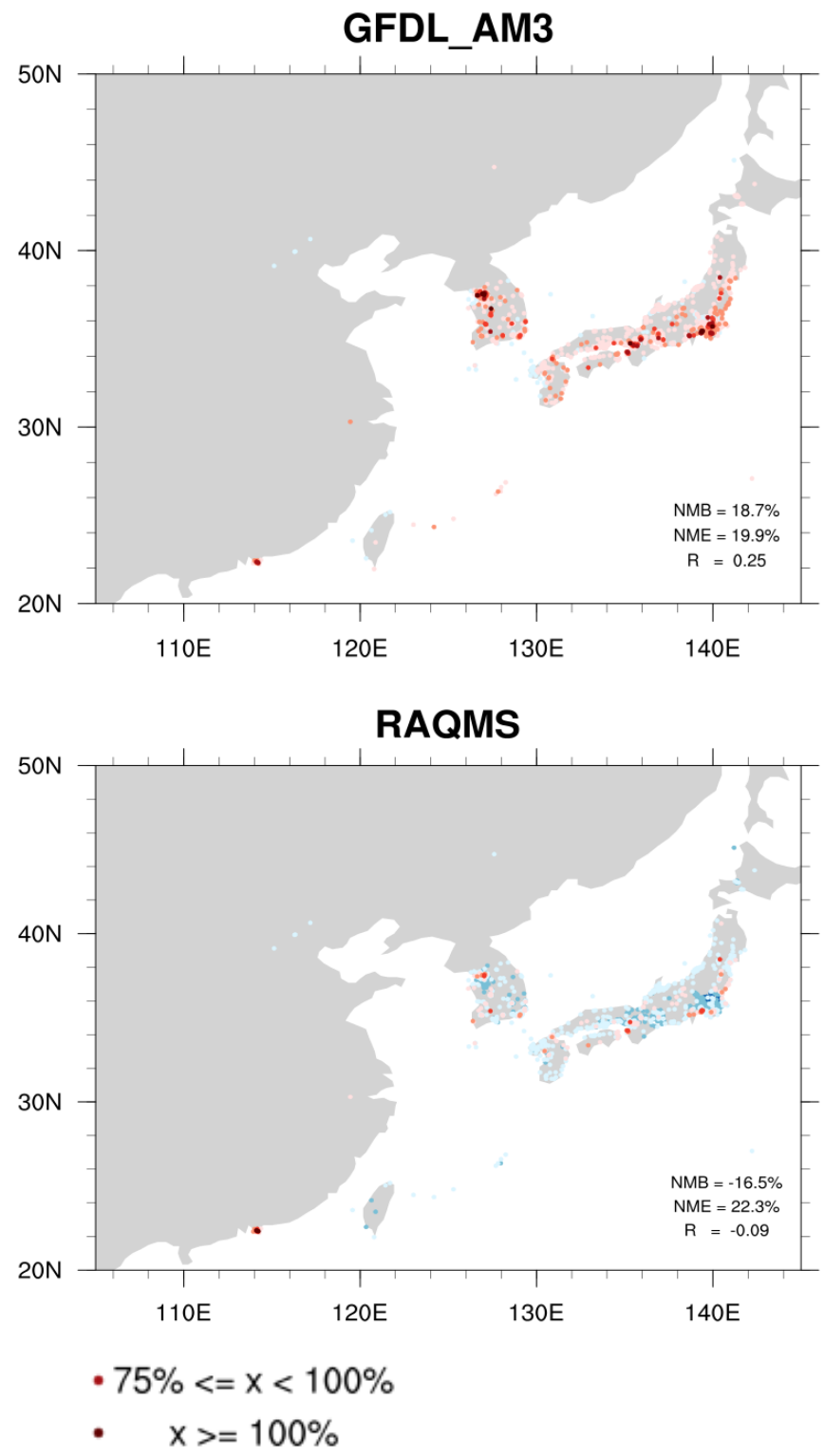

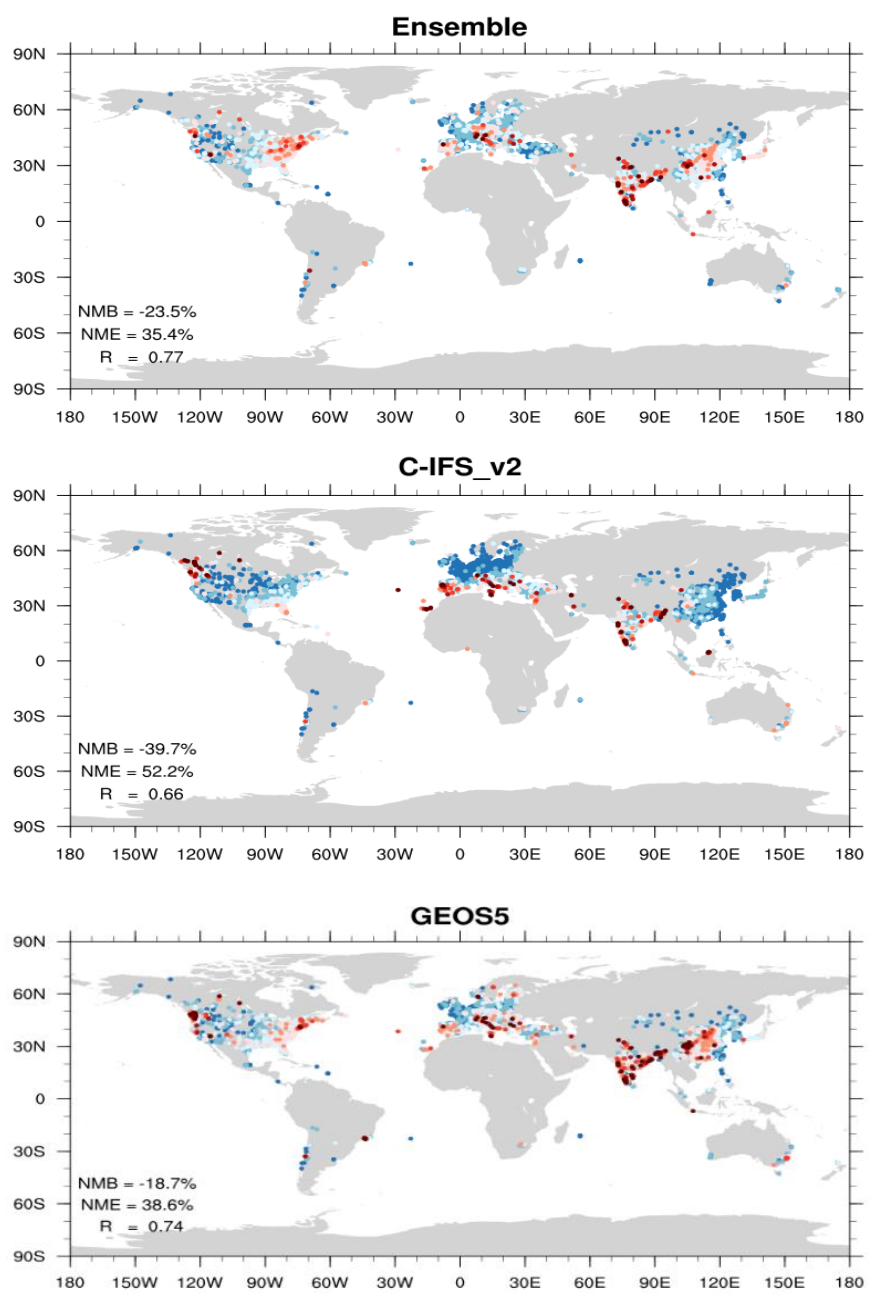

- $x<-50 \%$

$-50 \%<=x<-25 \%$

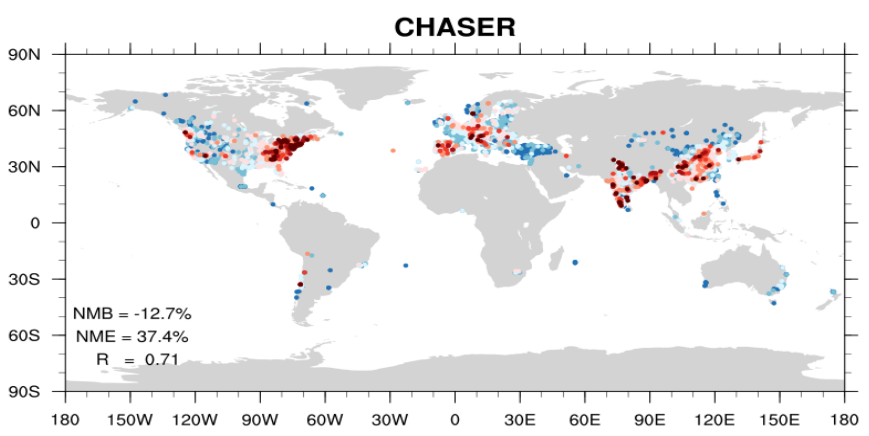

EMEP_rv48

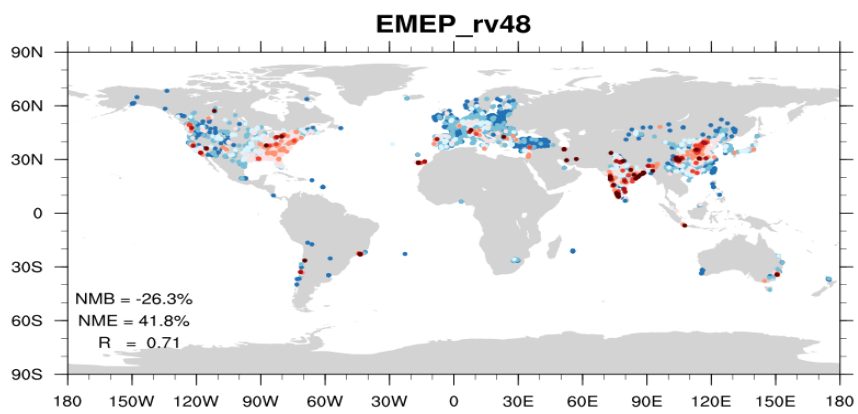

GocARTv5
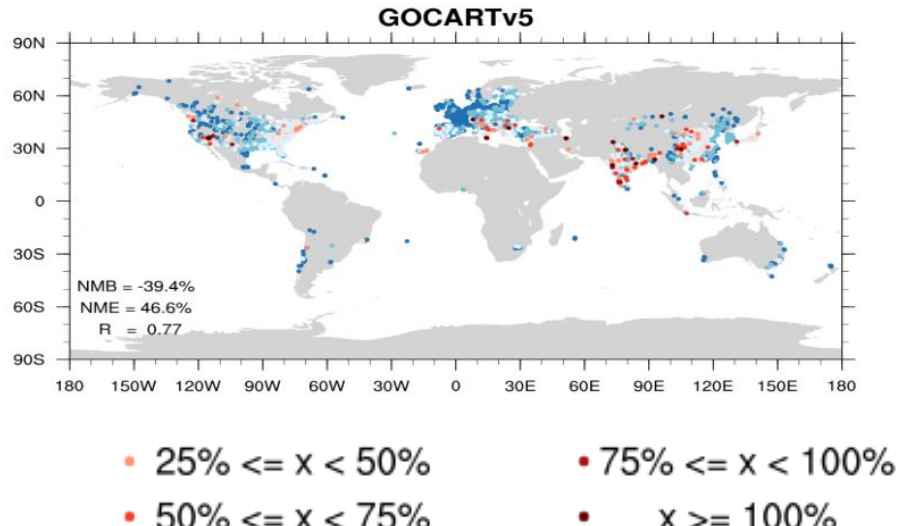

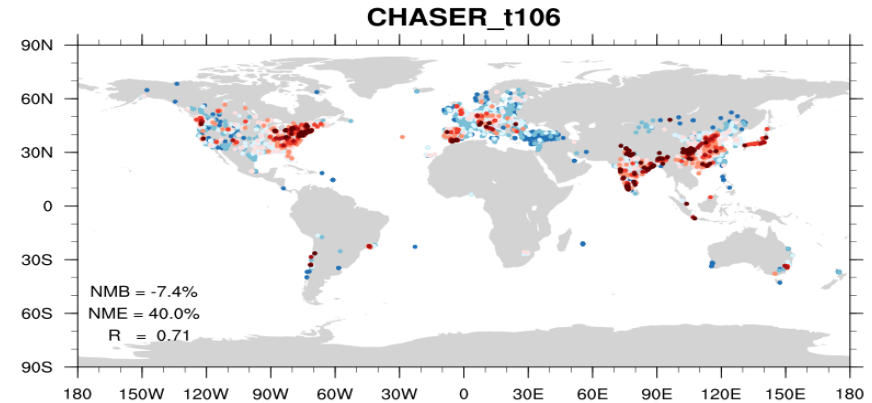

GEOSCHEMADJOINT

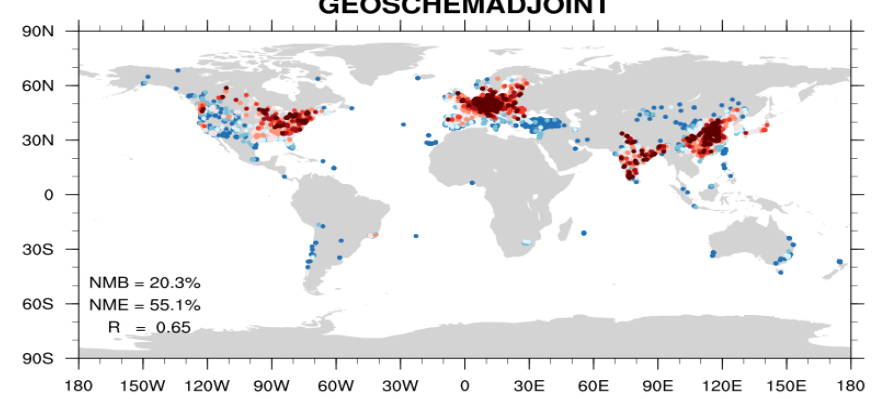

SPRINTARS

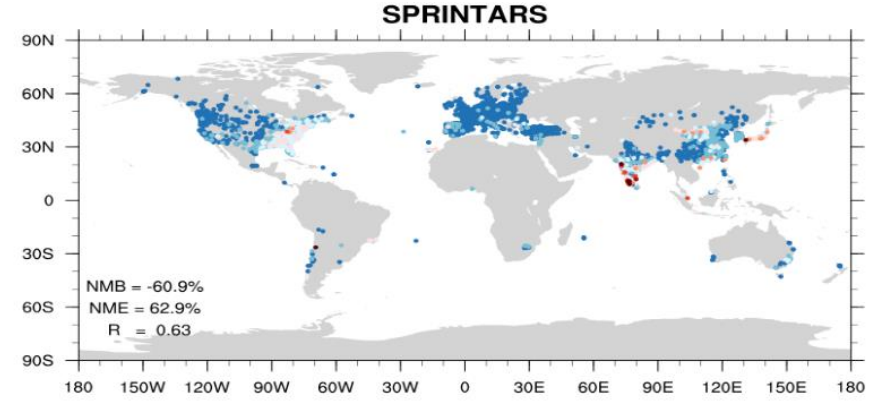

Figure S7. Spatial distributions of model performance for the annual average $\mathrm{PM}_{2.5}$, comparing GBD2015 observations with individual model simulations and the ensemble mean. The overall statistical parameters for each model are in the bottom left of the plot. 

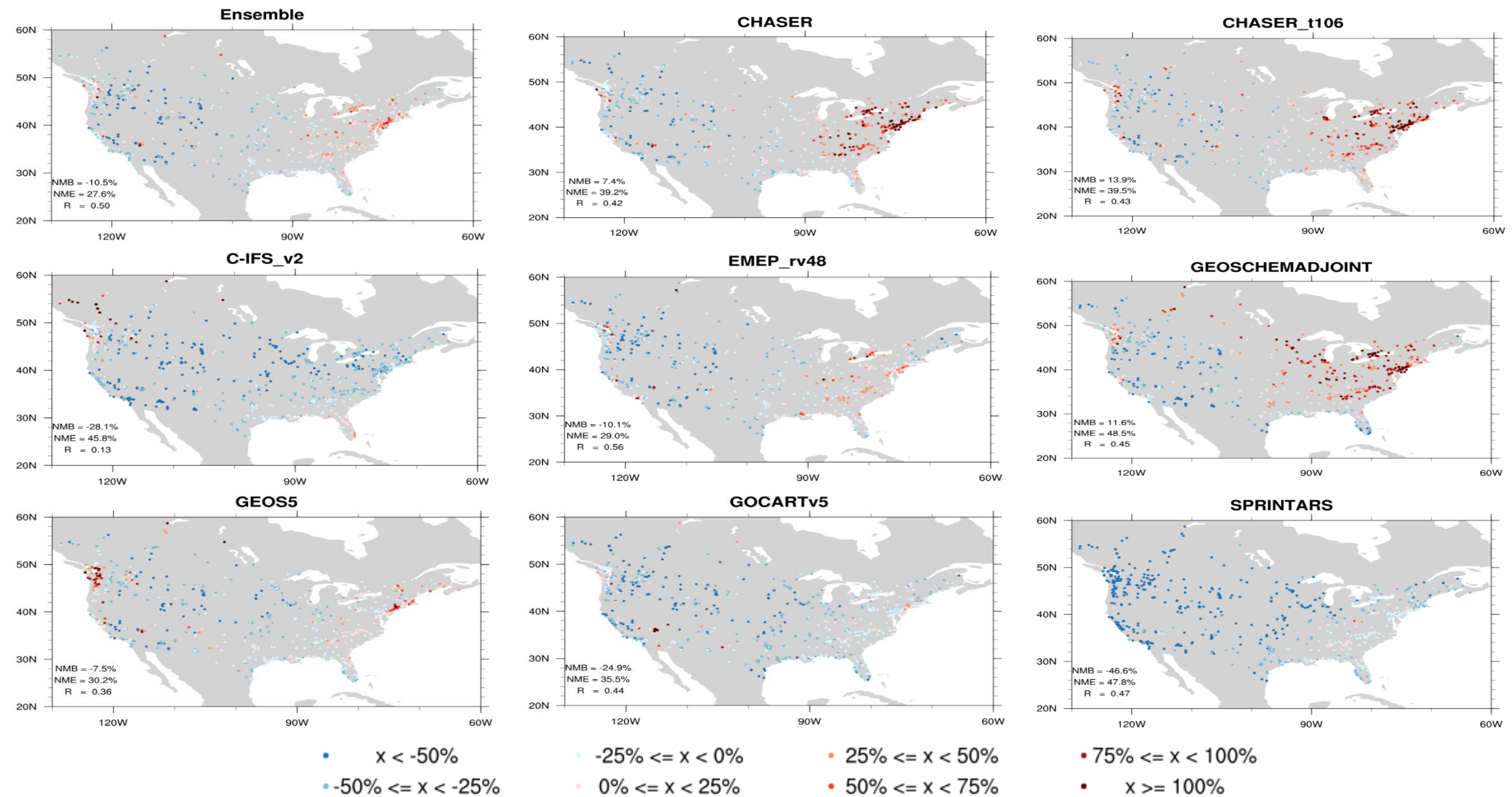

Figure S8. As Figure S7 but for NAM. 

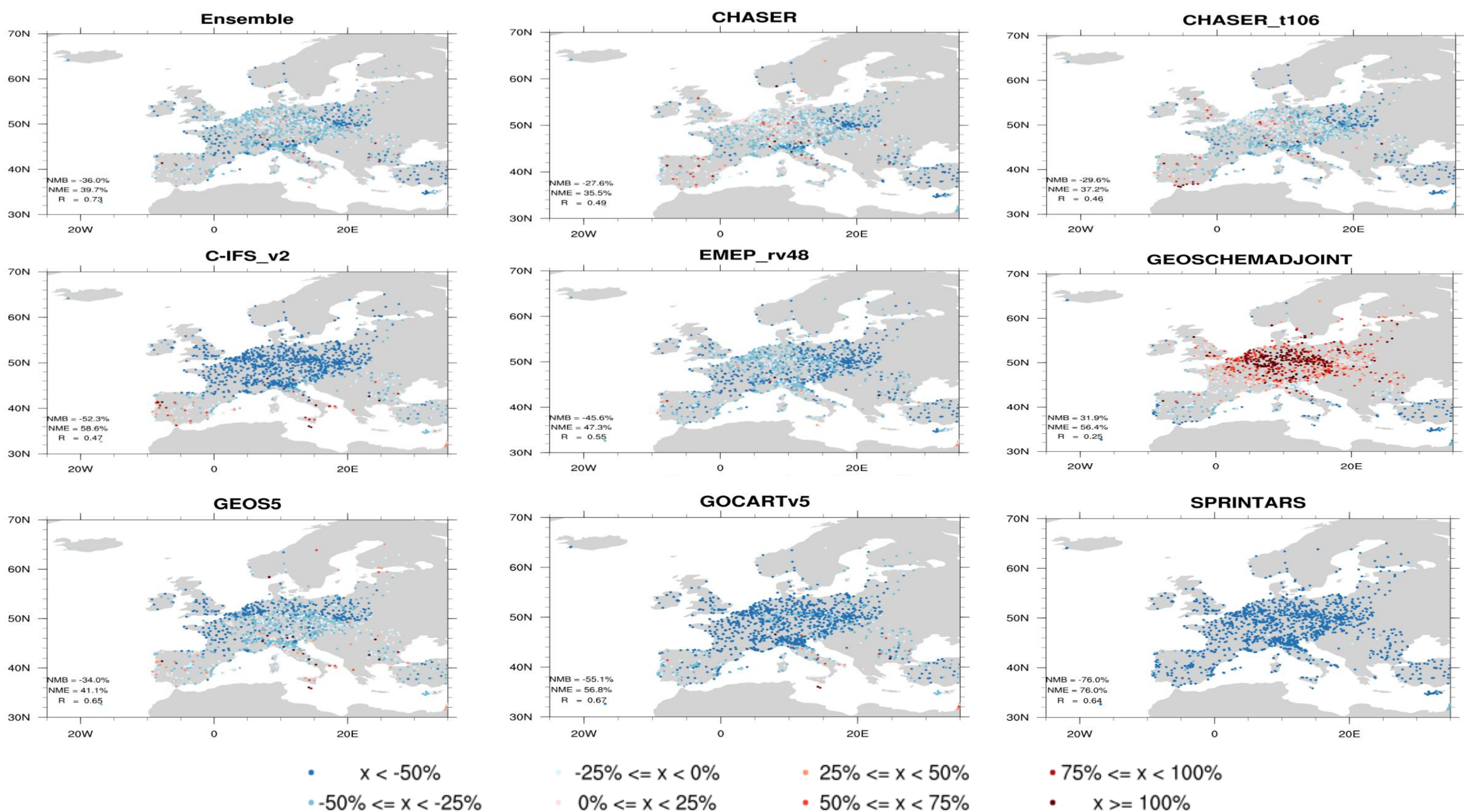

Figure S9. As figure S7, but for Europe. 

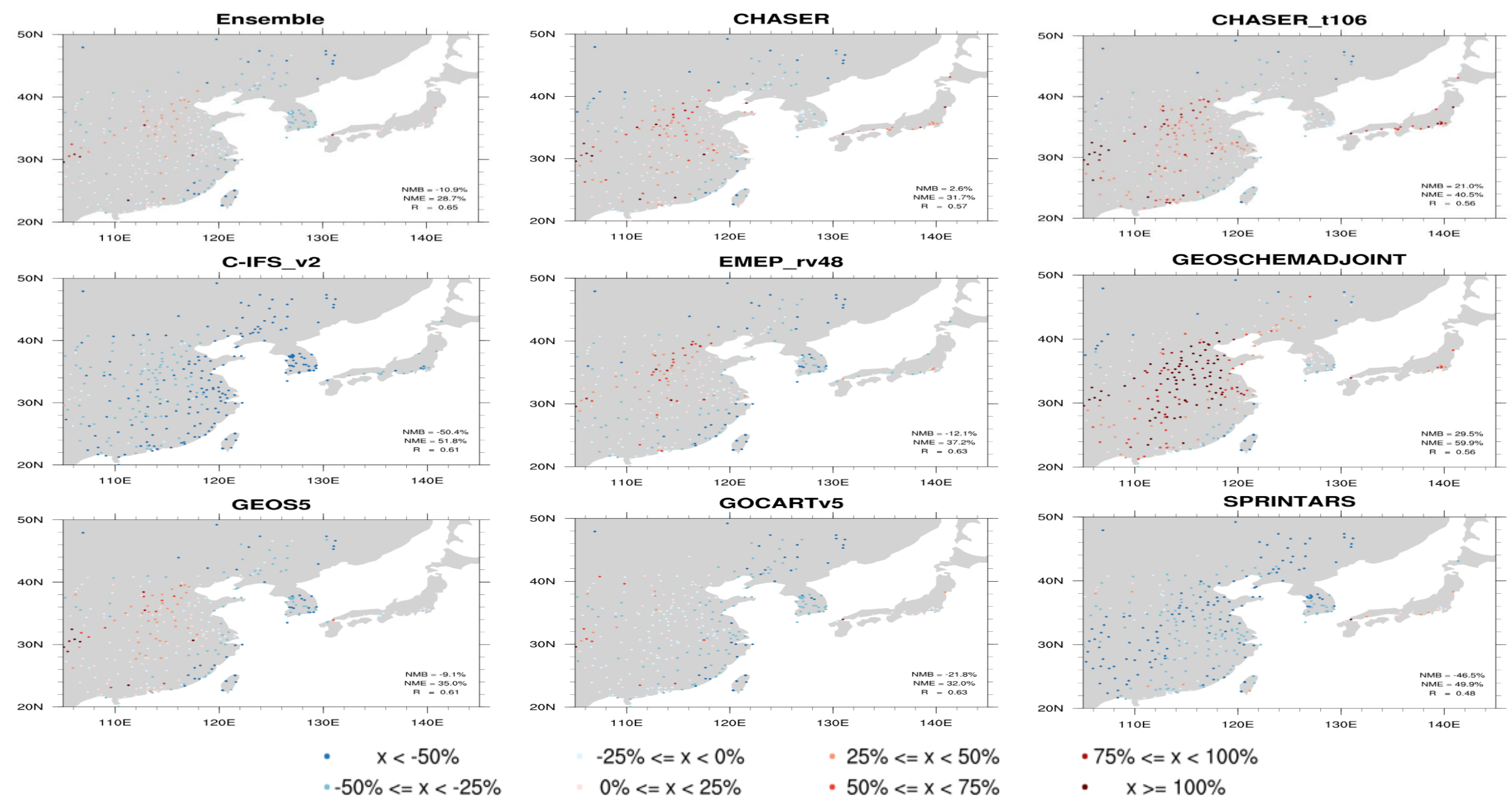

Figure S10. As Figure S7, but for East Asia. 
(a) Population

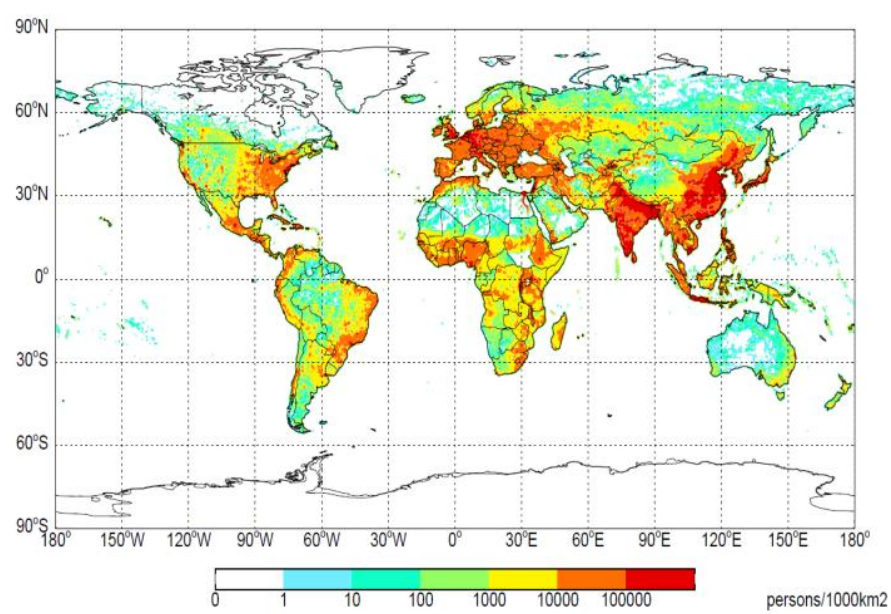

(b) Ischemic heart disease (IHD)
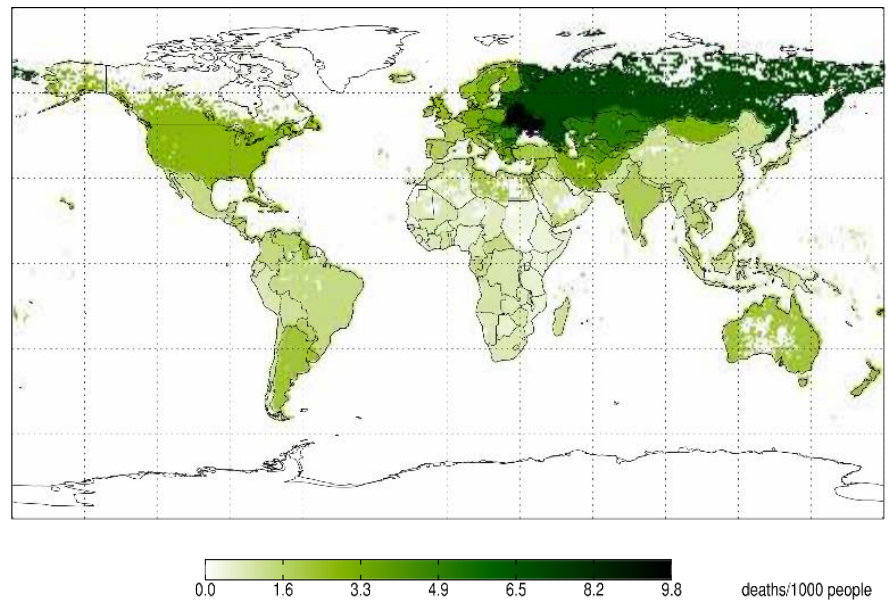

(c) Cerebrovascular disease (STROKE)
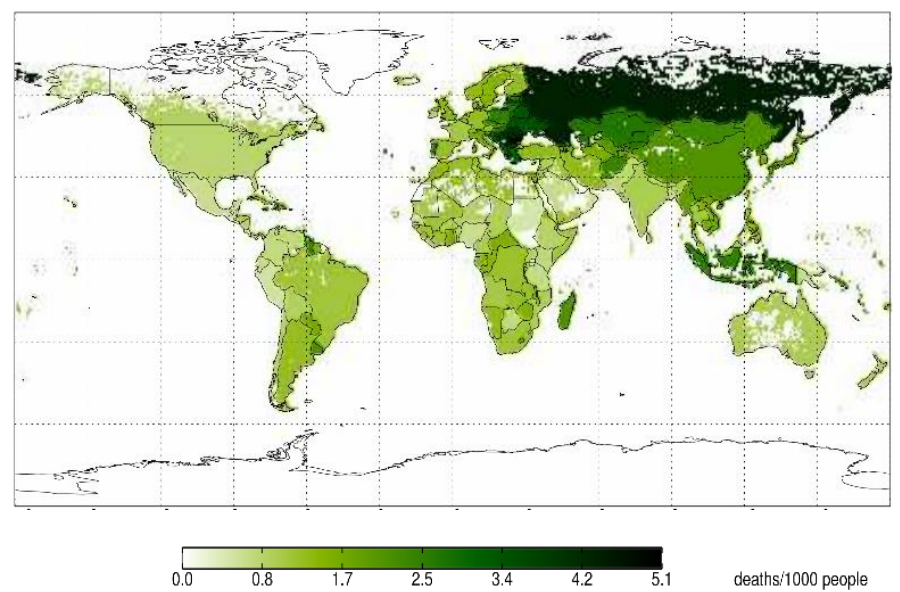

(d) Respiratory disease (RESP)

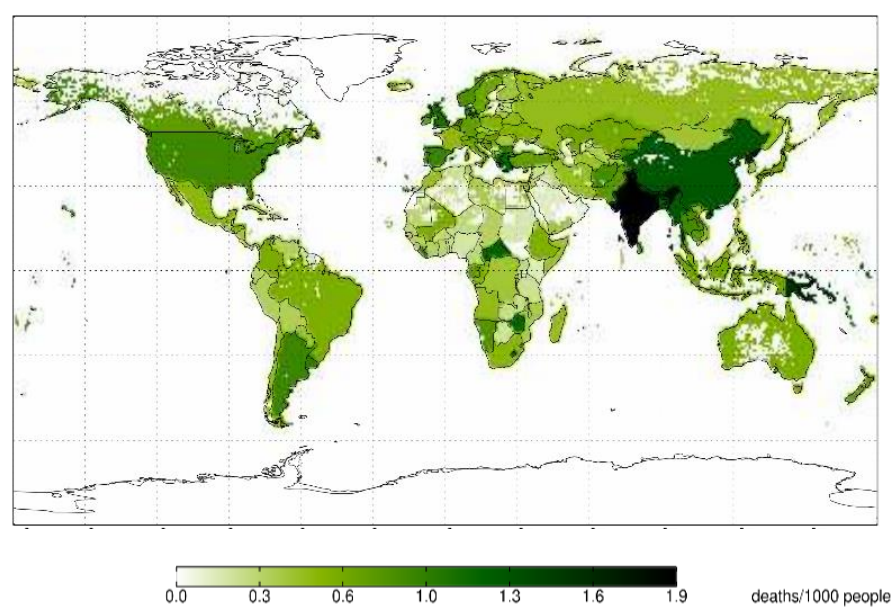

(e) Chronic obstructive pulmonary disease (COPD)
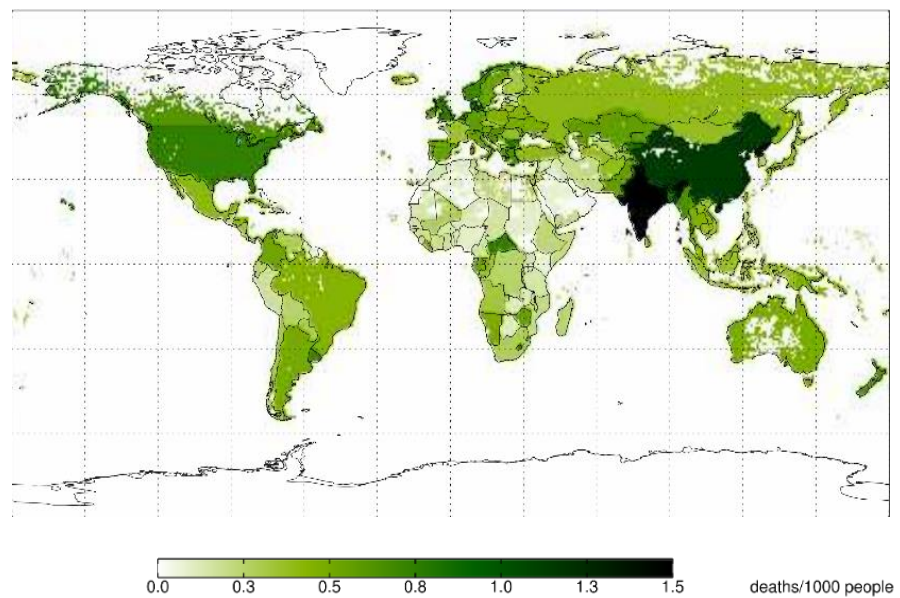

deaths/1000 people

(f) Lung cancer (LC)
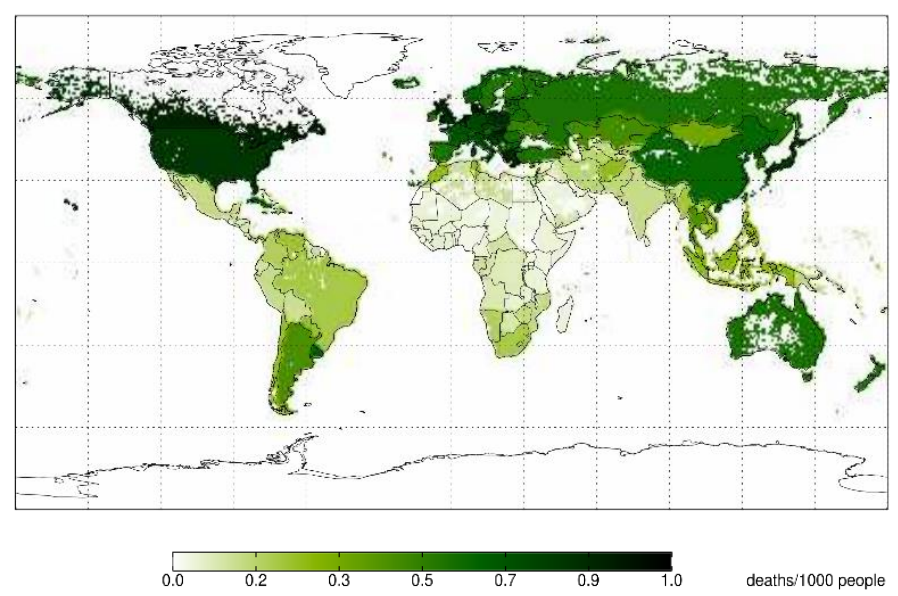

Figure S11- Spatial distribution of exposed population (people per 1,000 square kilometers) and the baseline mortality rates (deaths per year per 1,000 people) for adults aged 25 and above for specific mortality causes, at $0.5^{\circ} \times 0.5^{\circ}$ resolution in 2011 . The cause-specific baseline mortality rates for 187 countries are from the GBD 2010 mortality dataset (IHME, 2013) 


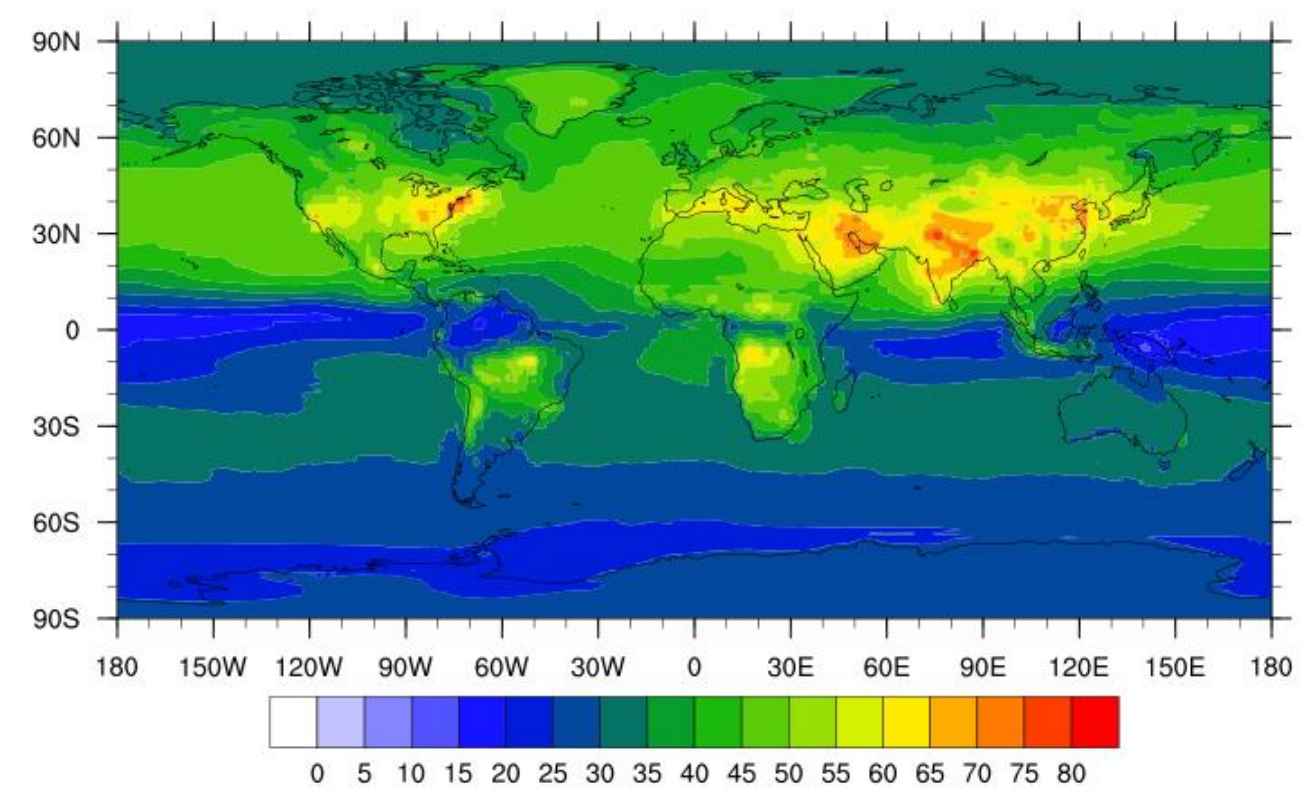

Figure S12 - Spatial distribution of $\mathrm{O}_{3}$ concentrations for the year 2010 (ppb), showing the multi-model mean (11 models) in each grid cell for the baseline.

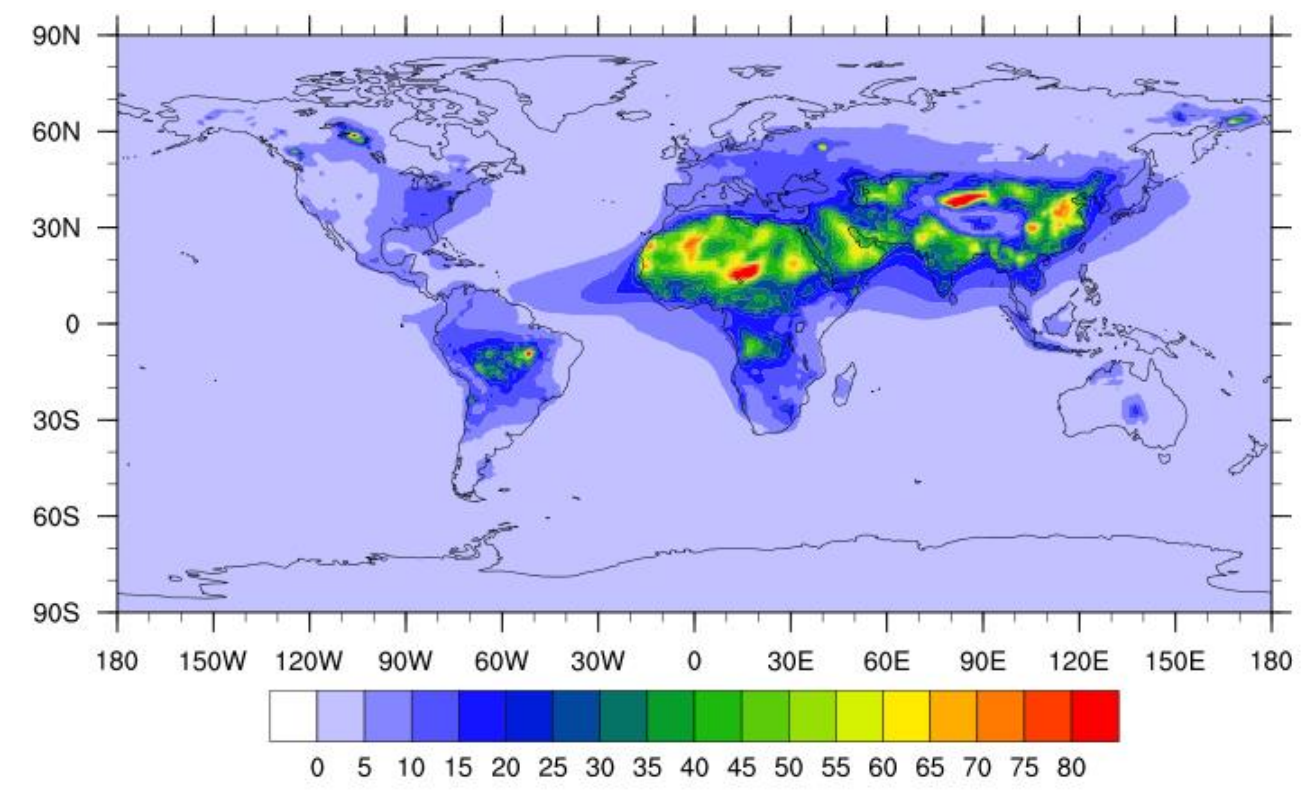

Figure S13 - Spatial distribution of $\mathrm{PM}_{2.5}$ concentrations for the year $2010\left(\mu \mathrm{g} / \mathrm{m}^{3}\right)$, showing the multi-model mean ( 8 models) in each grid cell for the baseline. 


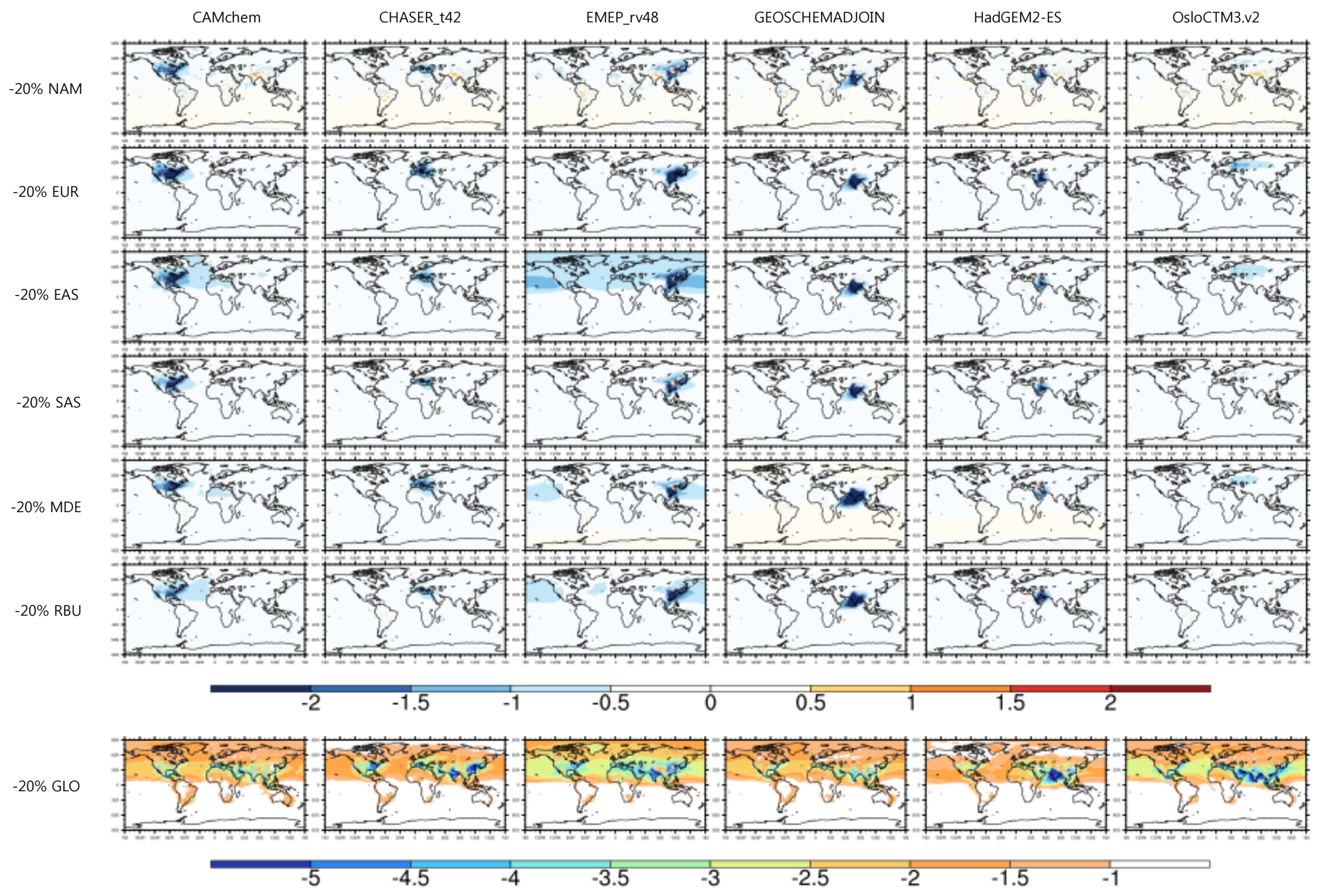


Figure S14 - The spatial distribution of the global difference in individual model $\mathrm{O}_{3}$ concentrations (ppb) in $20 \%$ emission reduction scenarios relative to the baseline for year 2010, for the 6-month $\mathrm{O}_{3}$ season average of 1-hr. daily maximums. 

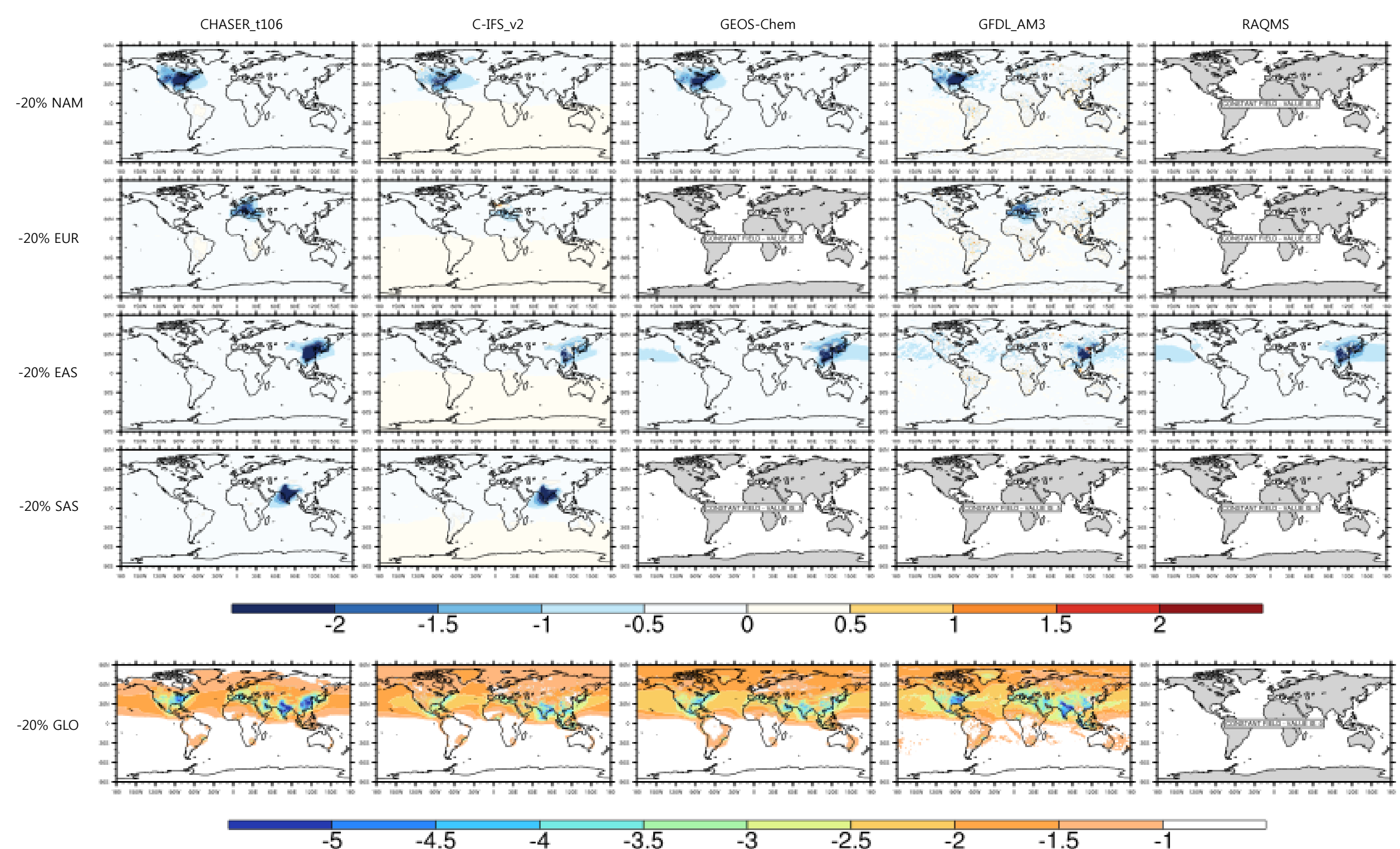

$-4.5$

$-4$

$-3.5$

$-3$

$-2.5$

$-2$

$-1.5$

Figure S14 - Continued. 
CHASER_t42

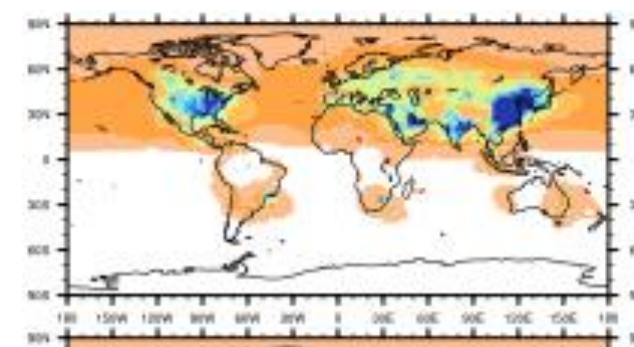

$-20 \%$ TRN

$-20 \%$ RES
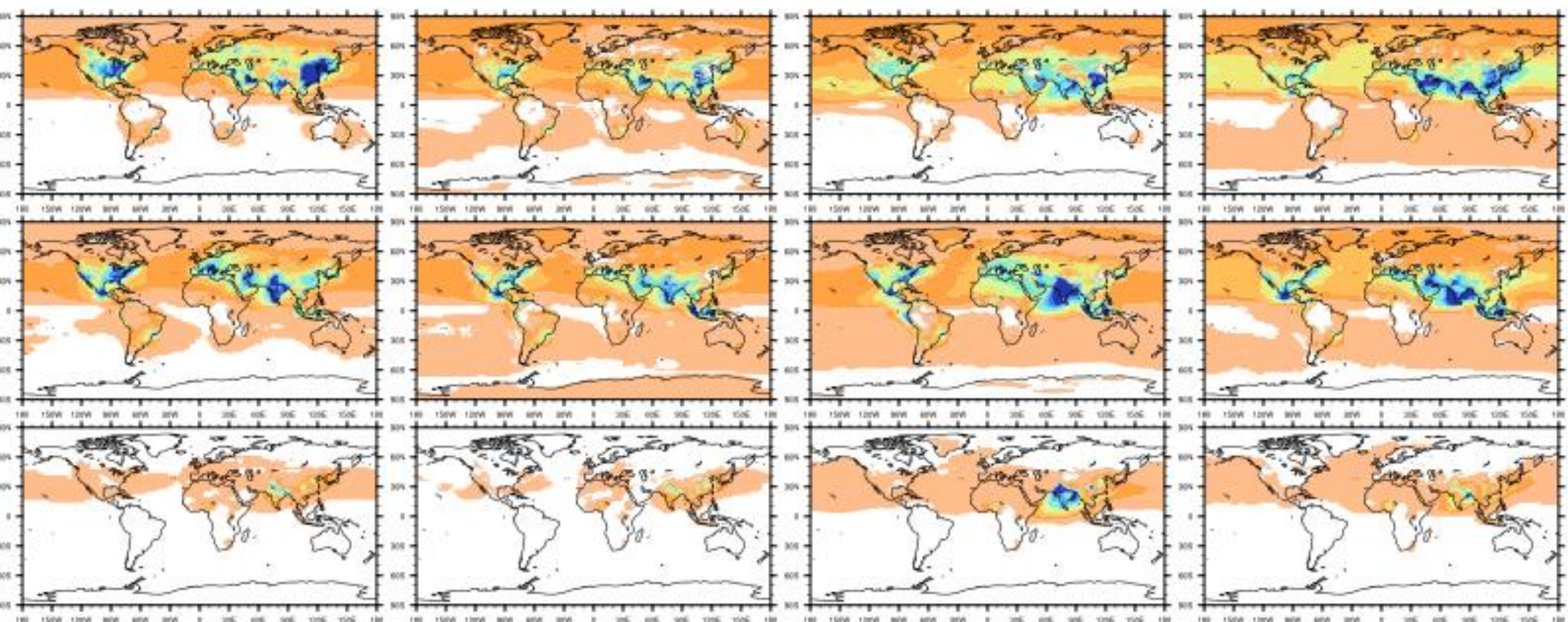

$$
\begin{array}{ll}
-1.8 & -1.6
\end{array}
$$

$-1.4$

$-1.2$

$-1$

$-0.8$

$-0.6$

$-0.4$

Figure S15 - As Figure S14, but for 20\% sectoral emission reductions. 


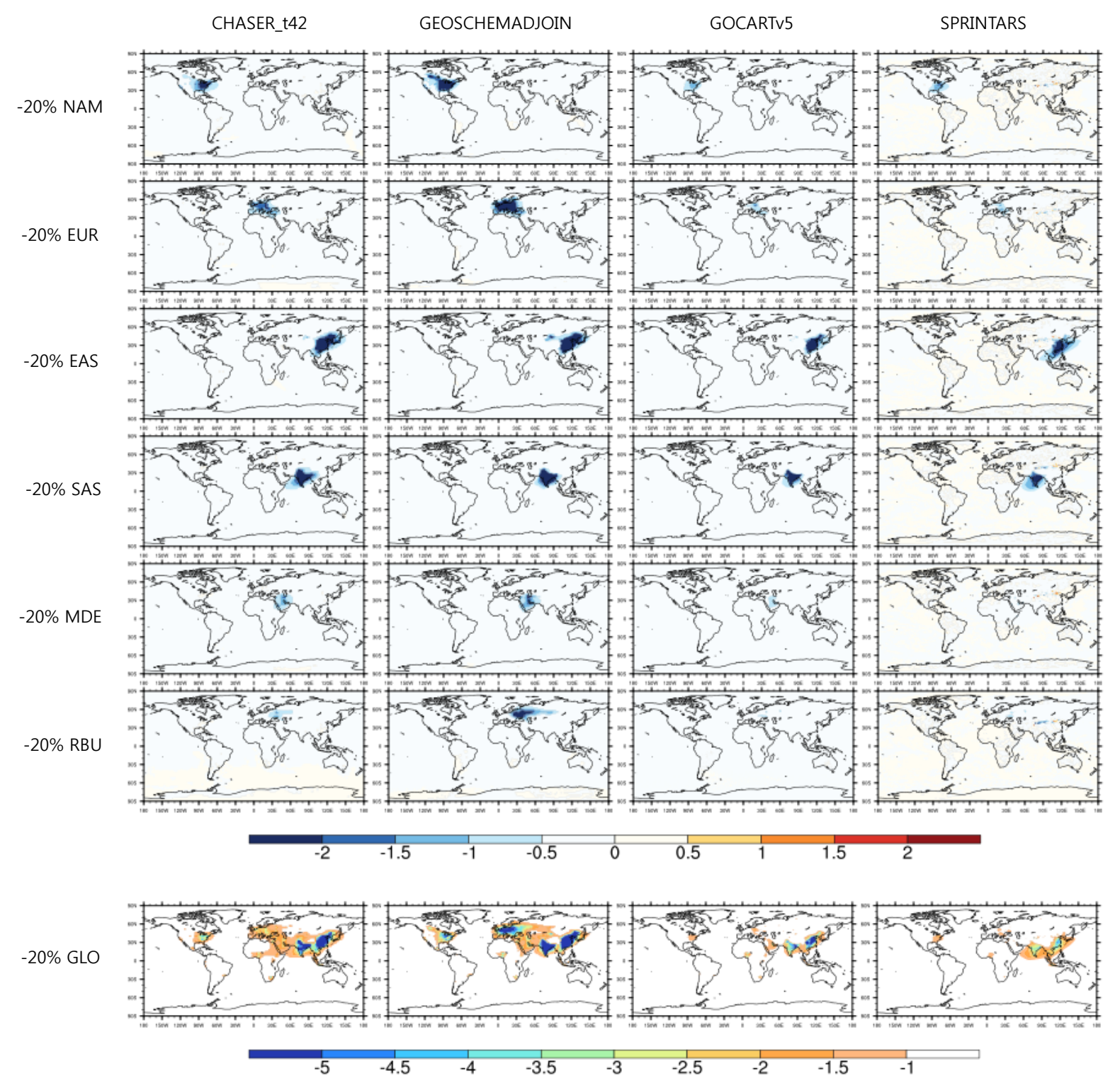

Figure S16 - The spatial distribution of the global difference in individual model annual average $\mathrm{PM}_{2.5}$ concentrations $\left(\mu \mathrm{g} / \mathrm{m}^{3}\right)$ in $20 \%$ emission reduction scenarios relative to the baseline for year 2010 . 


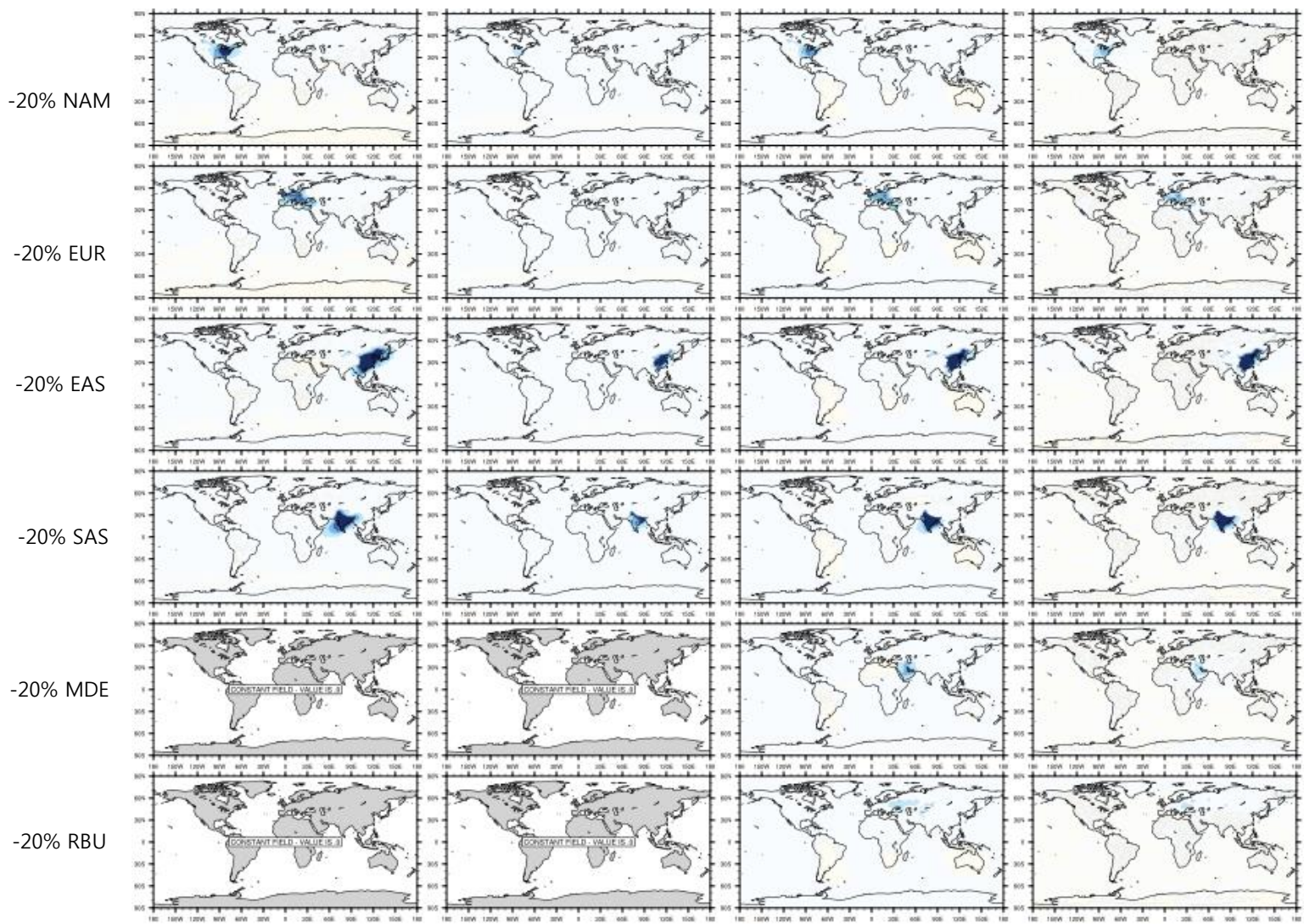

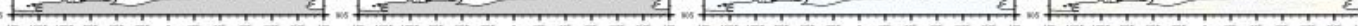

$-20 \%$ GLO

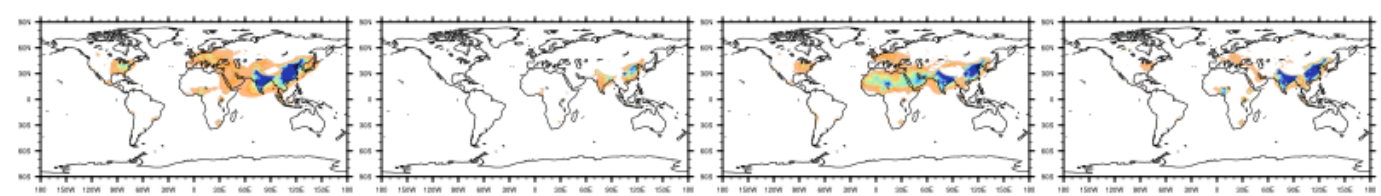

Figure S16 - Continued. 


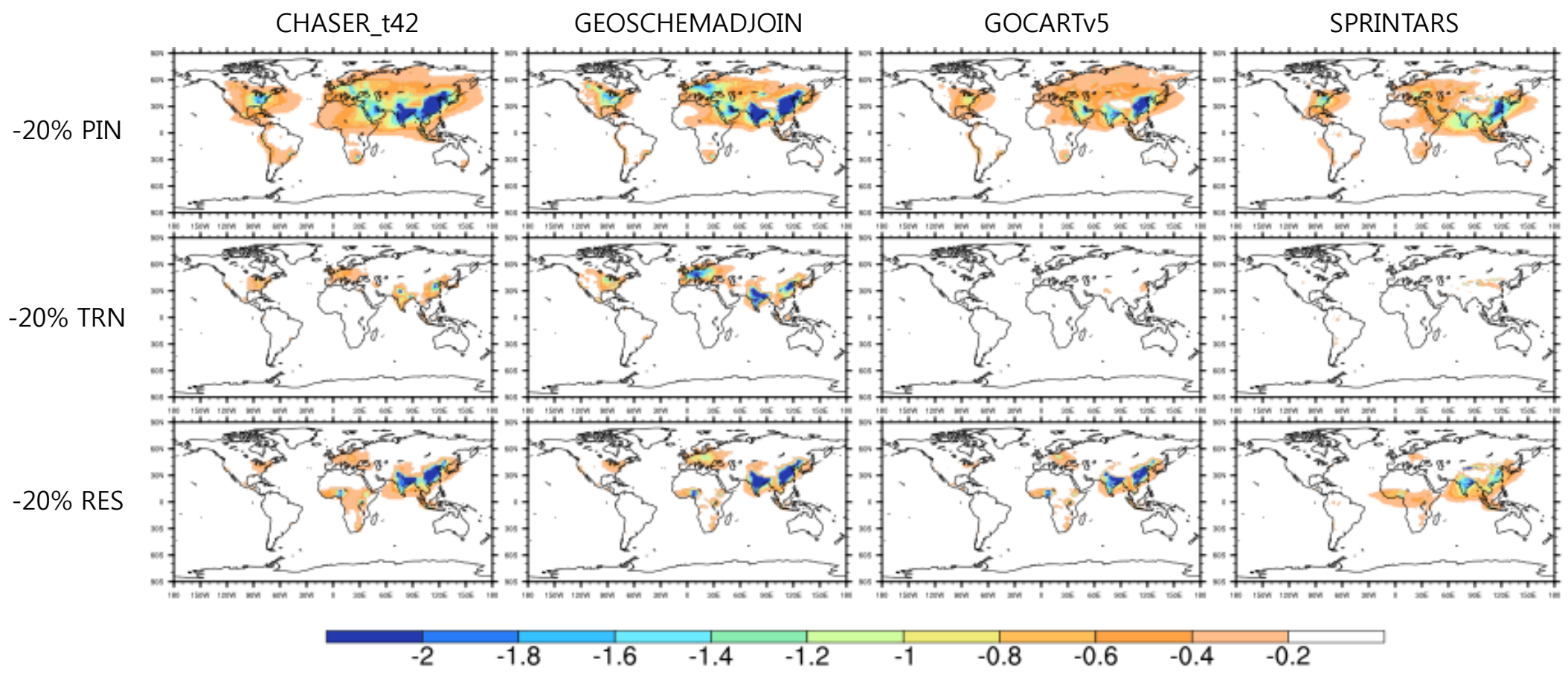

Figure S17 - As Figure S16, but for 20\% sectoral emission reductions. 


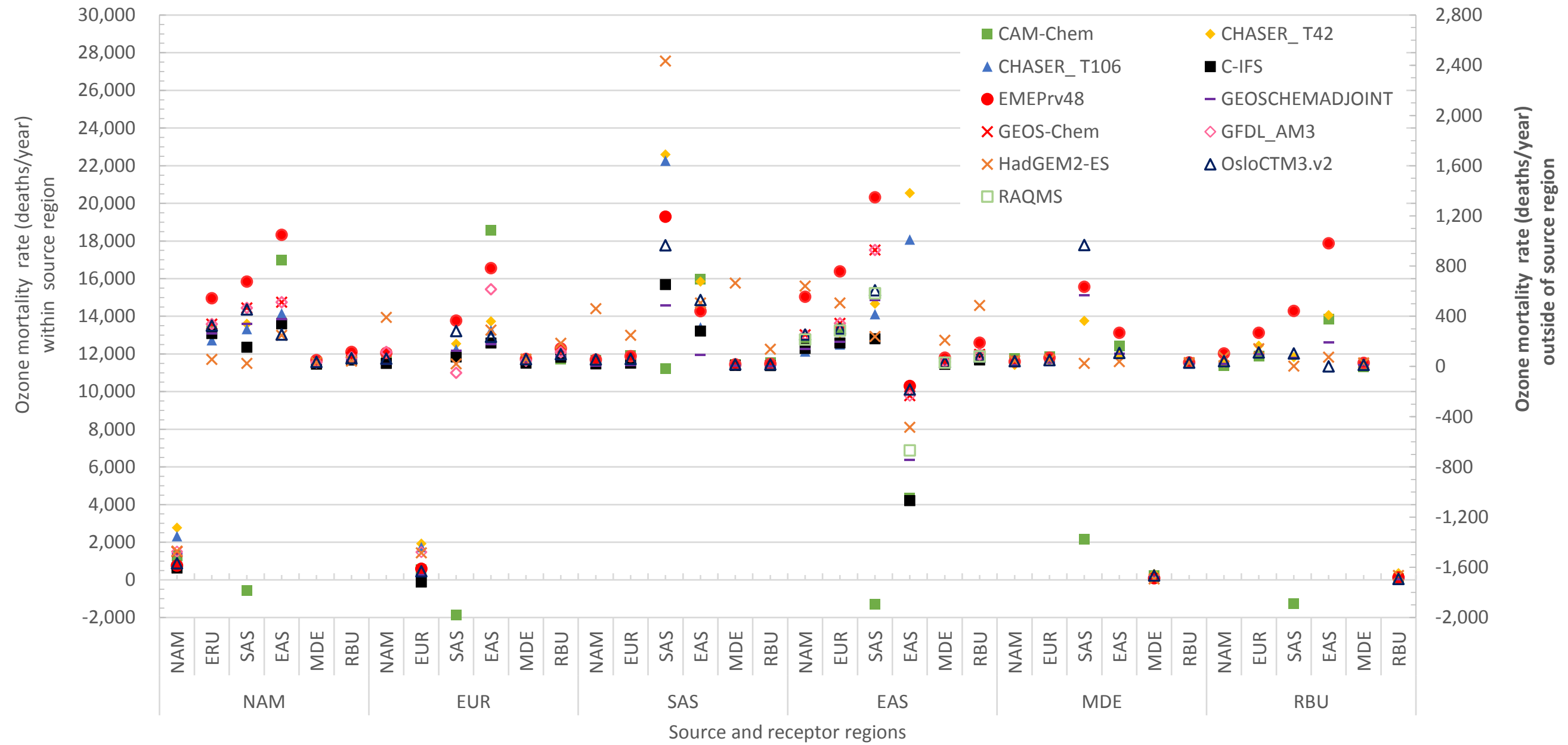

Figure S18 - Annual avoided $\mathrm{O}_{3}$-related mortality in each 6 receptor region due to $20 \%$ anthropogenic emission reductions in each 6 source region, as simulated by each of the 11 models. The left y axis shows the avoided deaths within source region itself, while the right represents the avoided deaths outside of the source region. The upper labels on $\mathrm{x}$ axis represent the receptor regions, while the six bottom labels represent the source region. 


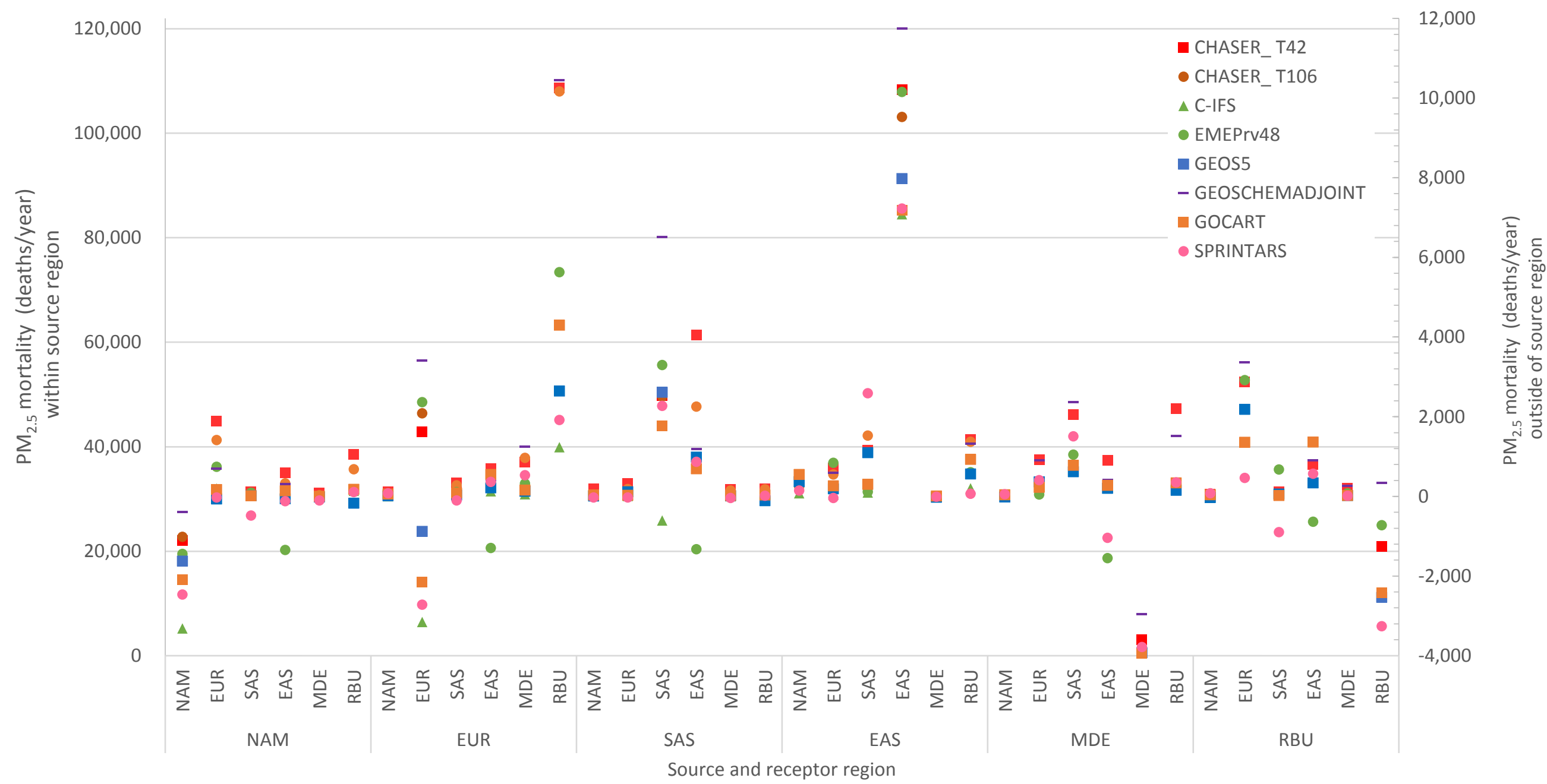

Figure S19 - Annual avoided PM2.5-related mortality in each 6 receptor region due to $20 \%$ anthropogenic emission reductions in each 6 source region, as simulated by each of the 8 models. The left y axis shows the avoided deaths within source region itself, while the right represents the avoided deaths outside of source region. The upper labels on $\mathrm{x}$ axis represent the receptor regions, while the six bottom labels represent the source region. 


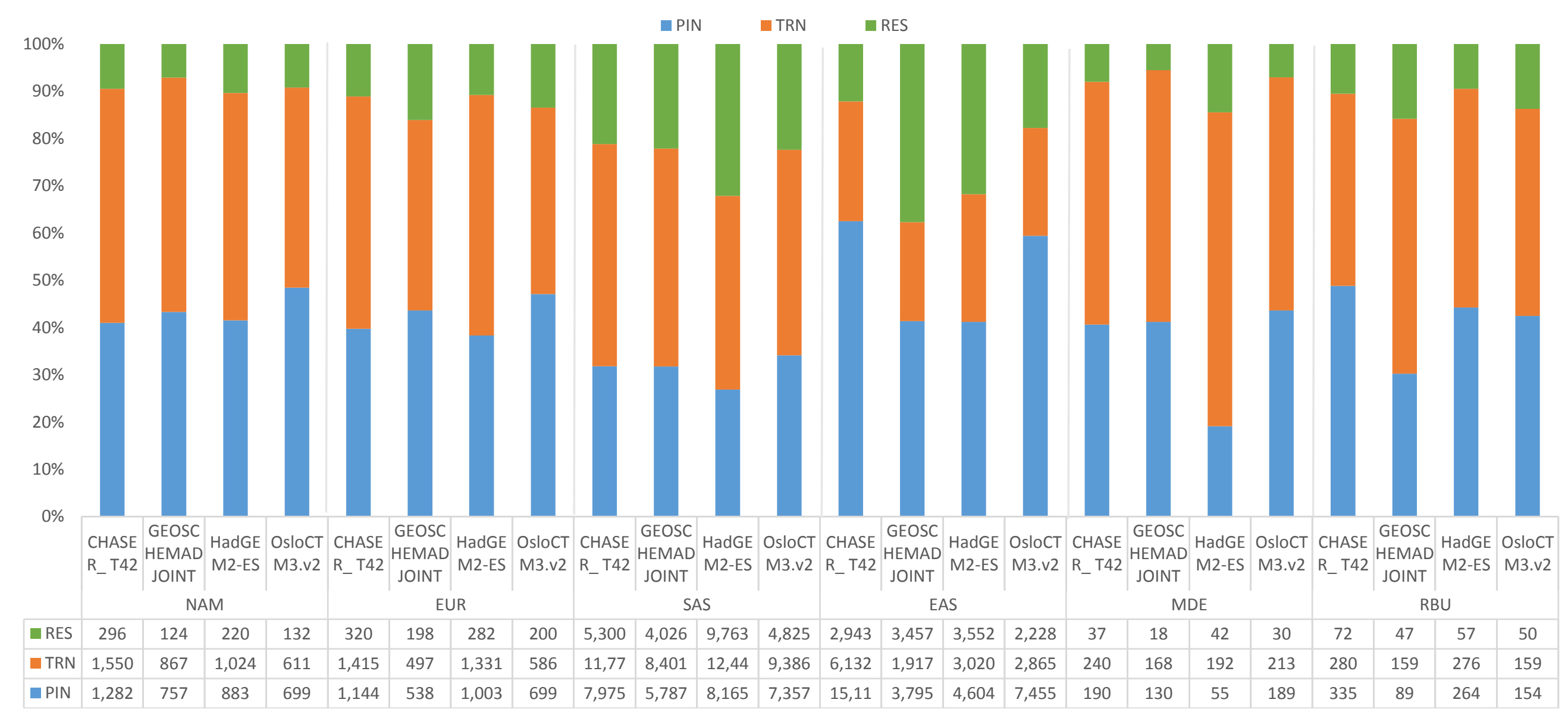

Figure S20 - Annual avoided $\mathrm{O}_{3}$-related mortality in the 6 receptor regions due to $20 \%$ anthropogenic emission reductions in 3 source sectors, as simulated by each of the 4 models. The value of y axis represents the percentage of total $\mathrm{O}_{3}$-related mortality (sum of 3 sectors) of each sectoral emission reduction for individual models and receptor regions. The upper labels on $\mathrm{x}$ axis represent individual model while the bottom labels on $\mathrm{x}$ axis represent the receptor regions. The table shows the number of $\mathrm{O}_{3}$-related avoided deaths from each sectoral emission reduction estimated by each model in each receptor region. 


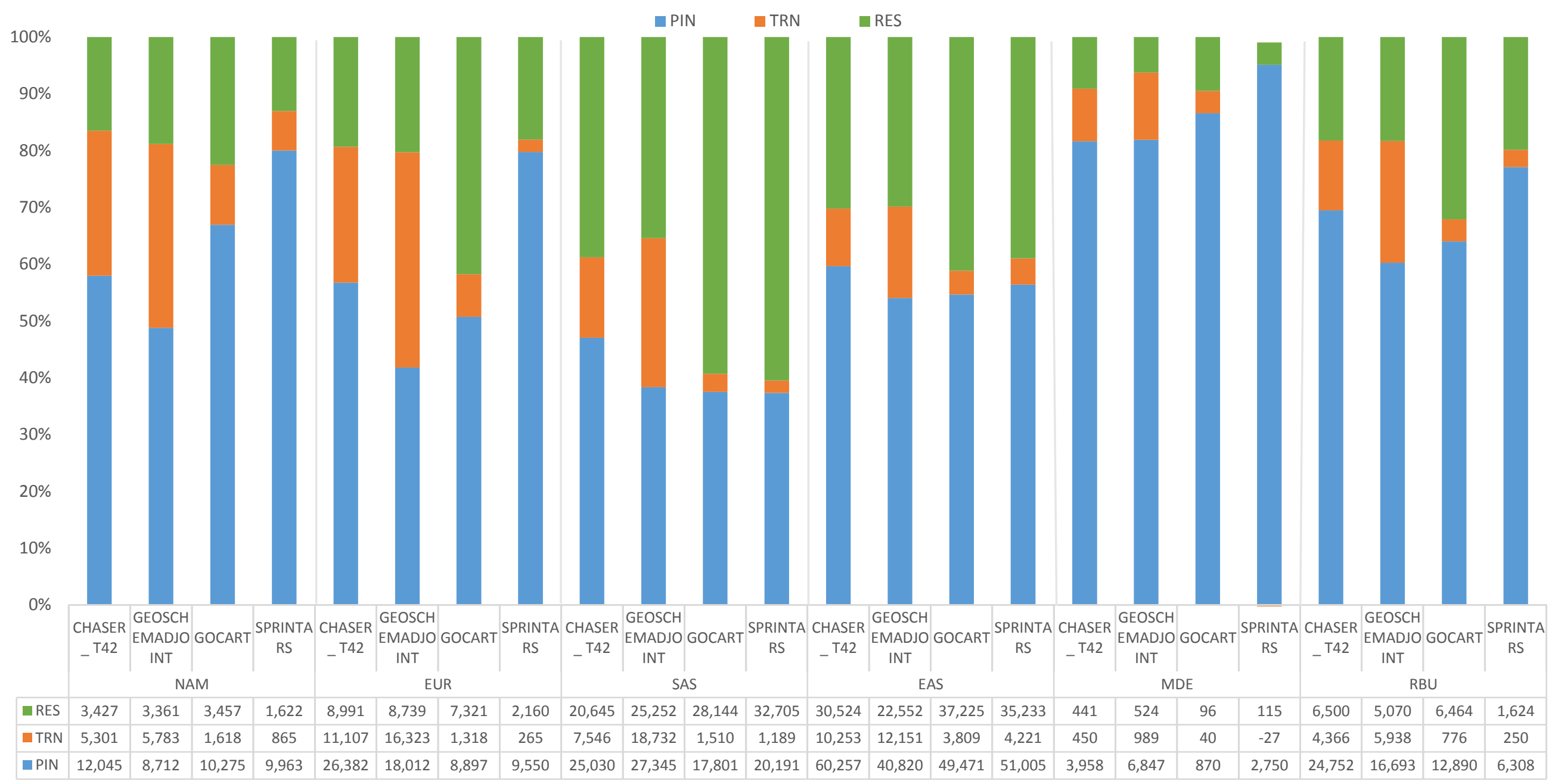

Figure S21 -Annual avoided $\mathrm{PM}_{2.5}$-related mortality in the 6 receptor regions due to $20 \%$ anthropogenic emission reductions in 3 source sectors, as simulated by each of the 4 models. The value of y axis represents the percentage of total $\mathrm{PM}_{2.5}$-related mortality (sum of 3 sectors) of each sectoral emission reduction for individual models and receptor regions. The upper labels on $\mathrm{x}$ axis represent individual models while the bottom labels on $\mathrm{x}$ axis represent the receptor region. The table shows the number of $\mathrm{PM}_{2,5}$-related avoided deaths from each sectoral emission reduction estimated by each model in each receptor region. 


\section{References}

Bright, E. A., Coleman, P. R., Rose, A. N., and Urban, M. L.: Land-Scan 2011, Oak Ridge National Laboratory SE, Oak Ridge, TN, 2012.

Bey, I., Jacob, D. J., Yantosca, R. M., Logan, J. A., Field, B. D., Fiore, A. M. et al.: Global modeling of tropospheric chemistry with assimilated meteorology: Model description and evaluation, J. Geophys. Res., 106, 23073-23096, 2001a

Chin, M., Ginoux, P., Kinne, S., Torres, O., Holben, B. N., Duncan, B. N., Martin, R. V.,Logan, J. A., Higurashi, A., and Nakajima, T.: Tropospheric aerosol optical thickness from the GOCART model and comparisons with satellite and sunphotometer mea- surements, J. Atmos. Sci., 59, 461-483, 2002.

Colarco, P., da Silva, A., Chin, M., and Diehl, T.: Online simulations of global aerosol distributions in the NASA GEOS-4 model and comparisons to satellite and groundbased aerosol optical depth, J. Geophys. Res.-Atmos., 115, D14207, doi:10.1029/2009JD012820, 2010

Collins, W. J., Bellouin, N., Doutriaux-Boucher, M., Gedney, N., Halloran, P., Hinton, T., Hughes, J., Jones, C. D., Joshi, M., Lid-dicoat, S., Martin, G., O’Connor, F., Rae, J., Senior, C., Sitch, S., Totterdell, I., Wiltshire, A., and Woodward, S.: Develop-ment and evaluation of an Earth-System model - HadGEM2, Geosci. Model Dev., 4, 1051-1075, doi:10.5194/gmd-4-1051-2011, 2011.

Flemming, J., Huijnen, V., Arteta, J., Bechtold, P., Beljaars, A., Blechschmidt, A.-M., Diamantakis, M., Engelen, R. J., Gaudel, A., Inness, A., Jones, L., Josse, B., Katragkou, E., Marecal, V., Peuch, V.-H., Richter, A., Schultz, M. G., Stein, O., and Tsikerdekis, A.: Tropospheric chemistry in the Integrated Forecasting System of ECMWF, Geosci. Model Dev., 8, 975-1003, doi:10.5194/gmd-8-975-2015, 2015. Henze, D. K., Hakami, A., and Seinfeld, J. H.: Development of the adjoint of GEOSChem, Atmos. Chem. Phys., 7, 2413-2433, doi:10.5194/acp-7-2413-2007, 2007

Institute for Health Metrics and Evaluation (IHME): Global Burden of Disease Study 2010 (GBD 2010) Results by Cause 1990-2010 - Country Level. Seattle, United States, 2013.

Jones, C. D., Hughes, J. K., Bellouin, N., Hardiman, S. C., Jones, G. ～S., Knight, ～J., Liddicoat, S., O'Connor, F. M., Andres, R. J., Bell, C., Boo, K.-O., Bozzo, A., Butchart, N., Cadule, P., Corbin, K. D., DoutriauxBoucher, M., Friedlingstein, P., Gor-nall, J., Gray, L., Halloran, P. R., Hurtt, G., Ingram, W. J., Lamar-que, J.-F., Law, R. M., Meinshausen, M., Osprey, S., Palin, E. J., Parsons Chini, L., Raddatz, T., Sanderson, M. G., Sellar, A. A., Schurer, A., Valdes, P., Wood, N., Woodward, S., Yoshioka, M., and Zerroukat, M.: The HadGEM2-ES implementation of CMIP5 centennial simulations, Geosci. 
Model Dev., 4, 543-570, doi:10.5194/gmd-4-543-2011, 2011.

Lin, M., Fiore, A.M., Horowitz, L.W., Cooper, O.R., Naik, V., Holloway, J., Johnson, B.J., Middlebrook, A.M., Oltmans, S.J., Pollack, I.B.: Transport of Asian ozone pollution into surface air over the western United States in spring. J. Geophys. Res., 117, D00V07, doi:10.1029/2011JD016961, 2012.

Lin, M.Y., Horowitz W., Payton R.,. Fiore A.M, Tonnesen G.: US surface ozone trends and extremes from 1980 to 2014: Quantifying the roles of rising Asian emissions, domestic controls, wildfires, and climate. Atmos. Chem. Phys., doi:10.5194/acp17-2943-2017, 2017.

Pierce, B., Schaack, T., Al-Saadi J., Fairlie T. D., Kittaka C., Lingenfelser G., Natarajan M. et al.: Chemical data assimilation estimates of continental U.S. ozone and nitrogen budgets during the Intercontinental Chemical Transport ExperimentNorth America, J. Geophys. Res., 112, D12S21, doi:10.1029/2006JD007722, 2007. Rienecker, M. M., Suarez, M. J., Todling, R., Bacmeister, J., Takacs, L., Liu, H.-C., Gu, W., Sienkiewicz, M., Koster, R. D., Gelaro, R., Stajner, I., and Nielsen, J. E.: The GEOS-5 Data Assimilation System - Documentation of Versions 5.0.1, 5.1.0, and 5.2.0, NASA, Publication series: NASA/TM; 2008-104606, Technical report series on global modeling and data assimilation; Vol. 27, 2008.

Sudo, K., Takahashi, M., Kurokawa, J.-I., and Akimoto, H.: CHASER: A global chemical model of the troposphere 1. Model description, J. Geophys. Res.-Atmos., 107, ACH 7-1-ACH 7-20, doi:10.1029/2001JD001113, 2002.

Simpson, D., Benedictow, A., Berge, H., Bergström, R., Emberson, L. D., Fagerli, H., Flechard, C. R., Hayman, G. D., Gauss, M., Jonson, J. E., Jenkin, M. E., Nyíri, A., Richter, C., Semeena, V. S., Tsyro, S., Tuovinen, J.-P., Valdebenito, Á., and Wind, P.: The EMEP MSC-W chemical transport model - technical description, Atmos. Chem. Phys., 12, 7825-7865, doi:10.5194/acp-12- 7825-2012, 2012.

Søvde, O. A., Prather, M. J., Isaksen, I. S. A., Berntsen, T. K., Stordal, F., Zhu, X., Holmes, C. D., and Hsu, J.: The chemical transport model Oslo CTM3, Geosci. Model Dev., 5, 1441-1469, https://doi.org/10.5194/gmd-5-1441-2012, 2012.

Tilmes, S., Lamarque, J.-F., Emmons, L. K., Kinnison, D. E., Marsh, D., Garcia, R. R., Smith, A. K., Neely, R. R., Conley, A., Vitt, F., Val Martin, M., Tanimoto, H., Simpson, I., Blake, D. R., and Blake, N.: Representation of the Community Earth System Model (CESM1) CAM4-chem within the Chemistry- Climate Model Initiative (CCMI), Geosci. Model Dev., 9, 1853-1890, doi:10.5194/gmd-9-18532016, 2016.

Takemura, T., Nozawa, T., Emori, S., Nakajima, T. Y., and Nakajima, T.: Simulation of climate response to aerosol direct and indirect effects with aerosol transportradiation model, J. Geophys. Res.-Atmos., 110, D02202, 
doi:10.1029/2004JD005029, 2005.

Watanabe, M., Suzuki, T., O’ishi, R., Komuro, Y., Watanabe, S., Emori, S., Takemura, T., Chikira, M., Ogura, T., Sekiguchi, M., Takata, K., Yamazaki, D., Yokohata, T., Nozawa, T., Hasumi, H., Tatebe, H., and Kimoto, M.: Improved Climate Simulation by MIROC5: Mean States, Variability, and Climate Sensitivity, J. Climate, 23, 6312-6335, doi:10.1175/2010JCLI3679.1, 2010 